\title{
¿QUÉ ES LO QUE IMPORTA EN EDUCACIÓN PARA LA CIUDADANÍA? EVALUACIÓN DE UN CUESTIONARIO PARA PROFESORES
}

\author{
What matters most in Education for Citizenship? \\ Assessment of a questionnaire for teachers
}

\section{Qu'est ce qui a de l'importance dans l'Éducation pour la Citoyenneté? Évaluation d'un questionnaire pour les enseignants}

\begin{abstract}
Agustín Godás Otero*, Miguel A. Santos Rego** y Mar Lorenzo Moledo**
* Facultad de Psicología. Campus Universitario Sur. Universidad de Santiago de Compostela.15782 Santiago de Compostela.Correo-e: agustin.godas@usc.es ** Facultad de Ciencias de la Educación. Campus Universitario Sur. Universidad de Santiago de Compostela. 15782 Santiago de Compostela.

Correo-e: miguelangel.santos@usc.es; mdelmar.lorenzo@usc.es
\end{abstract}

Fecha de recepción: marzo de 2009

Fecha de aceptación definitiva: julio de 2009

Biblid [(1130-3743) 21, 2, 2009, 95-129]

\section{RESUMEN}

La Educación para la Ciudadanía y los Derechos Humanos ha sido incorporada (2007) al currículo oficial en España como materia autónoma, que debe ser cursada por todos los alumnos de Enseñanza Primaria y Secundaria. Como es lógico, un cambio de este alcance social y educativo convierte de nuevo al profesorado en pieza básica del proceso, máxime cuando no ha cursado la materia en su formación inicial ni abundan los planes de formación continua basados en un diagnóstico de 
necesidades. En ese sentido, tratando de saber lo que piensan los profesores en activo, los autores han llevado a cabo un estudio, a partir de un cuestionario realizado al efecto, centrado en los conocimientos y actitudes de los profesores ante esa coyuntura curricular. Este artículo tiene como principal objetivo evaluar la calidad técnica de los ítems, la fiabilidad, la validez de constructo factorial y la validez predictiva del instrumento de medida propuesto. Además, se realiza un análisis de los ítems en términos de dificultad y discriminación. El instrumento ha sido aplicado a una muestra de 796 profesores de los citados niveles de enseñanza. Después de los análisis realizados, el cuestionario se demuestra sustantivamente válido para el propósito con el que fue construido.

Palabras clave: Educación para la Ciudadanía, validez, fiabilidad, profesorado no universitario, análisis de ítems, sistema educativo, currículo.

\section{SUMMARY}

The Education for Citizenship and Human Rights was incorporated (2007) to the Spanish official curriculum as an autonomous subject, which any pupil in primary or secondary education has to do. Obviously, when it comes to such a social and educational change, teachers are meant to be a basic part of this process, especially because this subject has not been studied initially and there are very few Lifelong Learning plans based on an assessment of needs. That is why, trying to find out what teachers think, the authors have carried out a study, based on a questionnaire to this purpose, focusing on teachers' knowledge and attitudes towards this particular curriculum situation. This article is aimed at assessing the technical quality of the items, reliability, construct validity and predictive validity of the factorial measurement instrument proposed. Furthermore, we carried out an item analysis in terms of difficulty and discrimination. The instrument has been applied to a sample of 796 teachers of primary and secondary education. After the analysis, the questionnaire was categorically demonstrated as valid for the purpose for which it was planned.

Key words: Education for Citizenship, validity, reliability, non university teachers, item analysis, educational system, curriculum.

\section{SOMMAIRE}

L'Éducation pour la Citoyenneté et les Droits de l'Homme a été intégrée (2007) au programme officiel en Espagne en tant que matière autonome, qui doit être suivie par tous les élèves de l'enseignement primaire et secondaire. Comme c'est bien logique, un tel changement social et éducatif, rend de nouveau aux professeurs leur importance comme éléments principaux du processus d'enseignement surtout étant donné le fait qu'ils n'ont pas étudié cette matière pendant leur formation initiale et il n'y a non plus un plan de formation continue fondé sur un diagnostic des nécessités. Dans ce sens, tout en essayant de découvrir ce qu'ils en pensent les professeurs 
en service, les auteurs ont réalisé une étude, basée sur un questionnaire à cet effet, en mettant l'accent sur les connaissances et les attitudes des enseignants face à cette conjoncture curriculaire. Évaluer la qualité technique des articles, de la fiabilité, de la validité de constructo factorial et la validité prédictive de l'instrument de mesure proposé. De plus, une analyse des items est réalisée dans des limites (termes) de difficulté et de discrimination. L'instrument a été appliqué à un échantillon de 796 professeurs des niveaux cités d'enseignement. Après les analyses menées à bien, le questionnaire se démontre nettement valable pour les buts pour lesquels il a été élaboré.

Mots clés: l'Éducation pour la Citoyenneté, validité, fiabilité, professorat non universitaire, análisis d'items, système éducatif, curriculum.

\section{INTRODUCCIÓN}

Hasta hace poco tiempo, España se encontraba entre los países, fuera y también dentro de la Unión Europea, que no tenían en su currículo escolar una materia directamente vinculada al aprendizaje y desarrollo de competencias cívicas por parte de las niñas y niños incorporados al sistema escolar, que en su etapa obligatoria va de los seis a los dieciseis años.

Para ser más exactos, tal circunstancia ha de entenderse referida a la presencia de una disciplina autónoma, con horario, programa y profesorado propio, que es justo lo que no teníamos y lo que ahora se está tratando de resolver con la Ley Orgánica de Educación (LOE) del 2006, texto normativo de la máxima cobertura legal para sancionar la existencia de lo que ya conocemos como Educación para la Ciudadanía y los Derechos Humanos.

Ahora bien, conviene decir con claridad que lo verdaderamente novedoso es la creación de una materia autónoma en el currículo oficial, obligatoria y evaluable como las demás materias pero, finalmente, reducida en su horario semanal. Naturalmente, sus ejes de desarrollo giran en torno a temas o problemas que afectan a la mejor construcción de una ciudadanía democrática, y que, por ello, deben ser objeto de conocimiento, análisis y valoración por el alumnado. Entre otros, los siguientes: Estado y Constitución, Democracia y Vida Política, el Estado de las Autonomías, los Derechos Humanos y la Justicia Social, las Relaciones de Género, Identidad y Cultura en un Mundo Globalizado, el Cuidado del Medio Ambiente, o la Resolución de Conflictos.

Se trata, pues, de articular un planteamiento más explícito y contingente a propósito de las grandes cuestiones propulsoras de la ciudadanía en sus dimensiones cognitiva, afectiva, social y conductual. El reto, en ese sentido, no es otro que el de complementar-que no eliminar- la perspectiva transversal presente en la Ley Orgánica General del Sistema Educativo (LOGSE) del año 1990, cuya vigencia se extendió hasta el comienzo del nuevo siglo. Siendo teóricamente válido (atravesar todas las materias del currículo mediante una educación en valores morales cívicamente orientados: educación vial, ambiental, para el consumo, 
para la igualdad entre los sexos...), el enfoque de la transversalidad se demostró totalmente insuficiente para ejecutar esa educación en valores democráticos a los alumnos en una época presidida por inequívocas revoluciones tecnológicas, comunicativas, sociales y culturales.

De todos modos, lo que pueda resultar novedoso debe, además, mostrar su relevancia sistémica. Es en ese sentido en el que proclamamos la necesidad, con sus ventajas añadidas, de compatibilizar una perspectiva transversal con otra basada en la creación de una disciplina autónoma. Sólo de esa manera se podrán poner a salvo criterios de solvencia pedagógica y de adecuado desarrollo curricular. Sin embargo, habrá que seguir insistiendo en que la educación para la ciudadanía no es tarea de la que se pueda desentender el profesorado de un centro sin encargo formal alguno en la impartición de la materia como tal. Primero, porque la tarea de todo profesor o profesora es de naturaleza cívica. Segundo, porque la dimensión moral y cívica es consustancial a todo el currículo y no a fragmentos o partes del mismo. Y tercero, porque la implicación de los demás colegas, por mínima que sea, ayudará a fortalecer la autonomía de esa disciplina en el currículo escolar, pudiendo servir de catalizador de ideas, inquietudes y proyectos, añadiendo valor a la motivación y al aprendizaje de los alumnos en un sentido más social.

Posibilidad y necesidad van aquí de la mano, tratando de que las perspectivas se encuentren en la voluntad de negociar y optimizar la situación. Tengamos presente, además, que quienes predican un cierto escepticismo tampoco son beligerantes en contra de la materia. Lo que hacen muchos es afirmar su pertinencia dudando (con toda legitimidad) de que esta formación se pueda reflejar en, o reducir a, una simple materia. Ser ciudadano, vienen a decir, exige contar con rasgos de carácter y hábitos conductuales que no resultan de ningún aprendizaje académico, sino del ejercicio de virtudes cívicas dentro y fuera de los centros escolares. Hablamos de una postura que cuenta, desde luego, con respaldo intelectual (ver Savater, 2005, 2007), y aun con la evidencia que nos proporciona el mundo de la vida real.

La fusión de ambas ópticas es la clave. Para beneficio de las personas, comunidad y democracia. En esa dirección, la visión y el pragmatismo expuestos por Puig (2006) parecen razonables. Conviene defender una materia porque proporciona la oportunidad de reflexionar sobre los conocimientos que dan soporte a la convivencia democrática. Pero también hay que procurar la implicación de los más jóvenes en actividades que, repetidamente, pongan en juego hábitos cívicos. Una fórmula, pues, sencilla y comprometida a un tiempo, sin otro secreto que la combinación de reflexión y experiencia (ver Santos Rego y Lorenzo Moledo, 2007, 2009).

Es cierto, no obstante, que el desafío pedagógico-curricular de la educación para la ciudadanía precisa, en su gestión de política educativa, de más y mejor formación del profesorado, equilibrando los componentes teóricos y prácticos de la misma, pero intensificando las propuestas orientadas a la reformulación de la cultura escolar, cuyos resortes cívicos han de considerarse en serio, a fin de que las prácticas morales sean identificadas y reforzadas. 
Tal vez por lo que acabamos de decir tendemos a dibujar la tarea docente como más cercana a lo procedimental y a la promoción de valores que a lo más propiamente instructivo. Lo cual no es ningún contrasentido. Eso sí, evitando confusiones o malos entendidos, tal como admiten Martínez, Puig y Trilla (2003: 93), pues una cosa es que los objetivos terminales de la función docente sean más procedimentales, actitudinales y éticos, y otra muy distinta que éstos puedan alcanzarse con modelos y propuestas formativas que no contemplen el trabajo sistemático y constante sobre contenidos de aprendizaje de carácter informativo y conceptual.

Por otra parte, independientemente de la discusión suscitada, creemos que las razones de política educativa, centrípeta y centrífugamente colocadas, ejercieron su influencia. Hay argumentos de filosofía política que avalan a un Estado democrático y de derecho para asegurar unos mínimos de aprendizaje cívico en y desde la escuela ( $c f r$. Mayordomo, 1998). Y en cuanto a los motivos supranacionales, no hemos de olvidar que en el marco de la política europea la promoción de la ciudadanía ha pasado a ser instrumento clave para fortalecer la democracia y la cohesión social (ver Eurydice, 2005).

Lo que decimos se ha puesto en evidencia dentro de la llamada "Estrategia de Lisboa", asociada al Education and Training Work Programme de la Comisión Europea (2001). El método usado para controlar los avances en la dirección educativa señalada fue, sencillamente, el uso de indicadores relacionados con la ciudadanía activa (ver Hoskins, Villalba, Van Nijlen y Barber, 2008).

Es un hecho que el tema de la ciudadanía y, más concretamente, de la competencia cívica, se ha convertido en uno de los focos de análisis político con más predicamento en la UE, toda vez que los países que la forman han coincidido en señalarla como una de las ocho competencias que se necesitan para que el éxito económico y una mayor inclusión social en Europa puedan avanzar a mayor ritmo. Hasta tal punto que el mismo Consejo ha querido disipar dudas afirmando que los resultados del aprendizaje individual requeridos para la ciudadanía activa deberían convertirse en uno de los 16 indicadores utilizados para medir el progreso de la Estrategia de Lisboa en relación con la Educación y la Formación (Education Council, 2007).

De todos modos, siendo incontrovertible, en nuestro marco de referencia social y cultural, la voluntad política de prestar atención a la educación para la ciudadanía y los derechos humanos, era de esperar que, paralelamente, se diseñasen y desarrollasen estudios de naturaleza empírica, centrados en la medición de variables, teórica y contextualmente significativas, de tan preciado constructo social. Sin embargo, la literatura científica en el campo no avala ese presagio, al menos con la fuerza que cabría esperar de las expectativas generadas.

Desde luego, el intento más ambicioso en la exploración de conocimientos, actitudes y conductas cívicas en edad escolar (conocimiento e implicación cívica en niños de 14 años) fue el que lograron capitanear Torney-Purta y su equipo, hace ahora una década, en 28 países de diversos continentes (Torney-Purta, Schwille 
y Amadeo, 1999; Torney-Purta, Lehman, Oswald y Schulz, 2001). El patrocinio correspondió a la Asociación Internacional para la Evaluación del Rendimiento Educativo (IEA) ${ }^{1}$. Como no podía ser de otra manera, dada la ausencia de la materia en sus disposiciones curriculares, España quedó fuera de la investigación, desarrollada en dos partes: primero se examinaron las expectativas en las diferentes latitudes, trazándose el consenso necesario sobre ejes comunes de contenido; con ello, en un segundo momento, se diseñó la prueba que había de aplicarse, y que incorporaba una serie de dominios centrales: democracia, instituciones y ciudadanía, identidad nacional, cohesión social y diversidad.

Para el estudio se construyeron tres instrumentos, que en realidad se correspondieron con otros tantos cuestionarios: uno para el estudiante, otro para la escuela como tal y, finalmente, otro para el profesorado. Pensando en el cuestionario del alumno se plantearon cinco tipos de ítems: contenido cívico, destrezas cívicas, comprensión de la ciudadanía, la democracia y el gobierno, actitudes, y participación política. En el que afectaba a la escuela (del que se encargaba la dirección) se preguntaba por el ambiente general del centro, sobre el modo de desarrollar la materia dentro del currículo, las actividades patrocinadas por la escuela y personal implicado en los temas cívicos.

De otro lado, el cuestionario dirigido a los profesores se dividía en tres partes: una centrada en la formación y experiencia laboral, otra acerca de sus perspectivas de la educación cívica y una más sobre la enseñanza de materias y actividades en todo lo relacionado con el tópico principal. Debemos decir que, para el caso de nuestro artículo, nos hemos fijado, básicamente, en los resultados de la aplicación del teacher questionnaire.

A fin de entenderlo bien, aportamos razones del mismo contexto. Como ya hemos dicho, en España se está empezando a impartir educación para la ciudadanía dentro del currículo escolar. Esto supone un cambio de notorio alcance en visión social y perspectiva pedagógica, aspectos que convierten, una vez más, al profesorado en piedra angular del proceso, pues al margen de su contribución es una quimera esperar efectividad en la dinámica emprendida. Por tanto, es lógico que intentemos saber lo que piensan los docentes en servicio activo, máxime cuando no han tenido formación inicial específica ni cuentan aún con un plan de formación continua basado en un adecuado diagnóstico de necesidades.

1. Un nuevo estudio, con los mismos auspicios, se llevará a cabo en 2009. La IEA ha ofrecido la posibilidad de incluir módulos específicos en las pruebas de los alumnos. Así, podría haber un módulo referido a los países europeos. Incluso hay un grupo de expertos encargado de elaborar y supervisar los ítems del citado módulo (para más información sobre este módulo, ver la página web http://iccs. acer.edu.au). La UE, que sufraga parte del coste que conlleva el Informe para sus países participantes, apoya el proyecto a través del Centro para la Investigación del Aprendizaje a lo largo de la Vida (Centre for Research on Lifelong Learning), dependiente de la Dirección General de Educación, de la Comisión Europea. 
De modo más explícito, pues, este trabajo sitúa su principal propósito en la evaluación de un cuestionario diseñado para examinar los conocimientos y las actitudes con los que cuentan los profesores de los niveles obligatorios de enseñanza ante la puesta en marcha de la materia "Educación para la Ciudadanía y los Derechos Humanos" en las escuelas españolas.

\section{2. ¿Qué entendemos por Educación para la Ciudadanía?}

De modo inevitable, las definiciones de Educación para la Ciudadanía se cuentan por centenares, razón suficiente para no intentar ningún análisis comparado, que nos alejaría de las intenciones que nos mueven en esta ocasión. Además, son muchas las variables de tipo histórico y contextual que tendrían que aducirse si nos adentráramos por esa pista de indagación (cfr. Lockyer, Crack y Annette, 2003; Banks, 2004; Lee et al., 2004; Colom y Rincón, 2007). El único criterio exigible a una dialéctica de tal envergadura moral es el de estar referida, exclusiva e inequívocamente, al lenguaje de la democracia, sin más condicionante que el de la libre decisión de las mujeres y hombres de un país.

En pocas palabras, no sería razonable pretender univocidad en objetivos, contenidos, metodología y formatos de evaluación cuando sabemos lo que influyen en ese cometido factores de tanto recorrido como los directamente relacionados con el contexto institucional y el marco sociocultural. Es más fácil que una institución supranacional sea más ambigua en el momento de definir la Educación para la Ciudadanía que otra de orden estatal o, si se prefiere, nacional; como lo es también que en un escenario autonómico o local se favorezcan mayores niveles de especificidad acerca de lo que conviene entender por buena dinámica en la construcción de una ciudadanía democrática.

Permítasenos aludir, eso sí, a una cuestión en la que la unanimidad es bastante manifiesta. Se trata de la preocupación por el logro de los máximos niveles de acercamiento posibles entre teoría y práctica. Lo que se deriva de la muy amplia literatura sobre el tópico es justo eso: que los conocimientos se complementen con una educación basada en la práctica. En los más destacados informes publicados sobre Educación para la Ciudadanía, incluyendo los realizados por la Comisión Europea y el célebre Informe Crick en Gran Bretaña, éste es un punto recurrente, lo mismo que el alusivo a la importancia de la formación del profesorado.

No puede extrañarnos que vaya cobrando fuerza entre nosotros el enfoque conocido como "Aprendizaje de Servicio" (Service Learning), pues lo que propone no es otra cosa que una metodología educativa consistente en ayudar a que los alumnos mejoren su aprendizaje cuando se implican en proyectos de servicio ( $c f r$. Puig et al., 2007; Santos Rego y Lorenzo Moledo, 2009). De acuerdo con el discurso pedagógico de John Dewey, del que emana históricamente este enfoque, no hay mejor manera de aprender algo que haciéndolo. Por lo cual, en la medida de lo posible, habría que procurar su incorporación al currículo escolar. Los alumnos han 
de aprender a identificar problemas en su entorno y a explorar distintos modos y estrategias para su afrontamiento

Tal vez no haya camino más corto a un modelo maximalista en la materia, tal como es referido por Martín Cortés (2006), que es el que repara no sólo en el logro de conocimientos (modelo minimalista), sino también en la necesidad de crecer en actitudes, habilidades y conductas. Porque, al final, el tema de fondo puede que pase por la resolución de un dilema susceptible de alterar el ánimo de no pocos docentes: aprobar o no a un alumno que sabe la teoría pero que es un ejemplo público y notorio de mal comportamiento con sus iguales y con sus profesores, dentro y fuera del aula ( $c f r$. Rivera, 2007). Tal prejuicio intelectualista existe y puede hacer daño a la materia. Si la sabiduría teórica no es condición necesaria ni suficiente para la sabiduría práctica, desde ésta haremos bien en solicitar algo más que un recital sobre conocimientos adquiridos en el tiempo (menguado) que el currículo le ha reservado.

Creemos que, con lo que llevamos dicho, no será difícil intuir nuestra particular concepción de este ámbito de trabajo educativo, dentro y fuera de las aulas. Pues bien, lo que nosotros entendemos por Educación para la Ciudadanía es un conjunto de conocimientos, destrezas y actividades susceptibles de contribuir a la gradual alfabetización política de niños y jóvenes en una sociedad democrática, con especial énfasis en la asunción responsable de derechos y deberes, la participación activa en la vida social y la formación de un juicio crítico.

Desde luego, en la perspectiva que defendemos, la ciudadanía se nutre de sus raíces morales, por lo que, aceptando una posición de Carr (2006), no hemos de agotar el recorrido de su alcance y significados -que bien podrían ser amparados por una ética de la responsabilidad social- en la exclusiva apelación a los derechos que asisten a las personas en una democracia. Los deberes también cuentan, y mucho, en la construcción cívica de los estudiantes.

Considerando los supuestos principales de la definición que nos permitimos ofrecer en este trabajo, debería deducirse una recomendación favorable a que los profesores intentemos convertir las clases de la materia en comunidades de aprendizaje, donde los estudiantes sean animados a implicarse en actividades y proyectos colaborativos. Las escuelas forman parte del espacio público y, sin perjuicio de la formación moral individual, los alumnos deben aprender a ser responsables en el terreno de lo común. Y aunque haya diferencias de grado en los puntos de vista, puede que no alcancen el umbral de lo categórico.

Tratemos de ser claros: educar para la ciudadanía es sinónimo de educar para la autonomía y la responsabilidad (Escámez y Gil, 2001; Ortega y Mínguez, 2001), clarificando así el sentido pragmáticamente moral de su mensaje y de sus propuestas pedagógicas, que no deben ser circunscritas o relacionadas sólo con la escuela, ya que son más las instancias de la sociedad civil que ejercen efectos educativos sobre la ciudadanía. De modo inequívoco, es una función, una tarea compartida con la familia, con los medios de comunicación, con las autoridades y administraciones, con la clase política, con el mundo asociativo. El eje del gran 
debate seguirá siendo dónde colocar la preferencia o, si se prefiere, la delegación de esa responsabilidad ( $c f r$. García Garrido, 2008).

Insistimos en este aspecto porque, aunque la obligación educativa es antes de la familia que de la escuela, ésta no puede inhibirse de la misma, incluyendo, naturalmente, la formación moral y cívica. Esto que decimos no es nuevo. Ya en los años setenta del siglo pasado Freinet recogía en su obra La educación moral y cívica: "La escuela no puede desinteresarse por la formación moral y cívica de los alumnos, porque sin ella no puede haber formación auténticamente humana" $(1972,7)$. Uno de los males del sistema que tenemos es la falta de complicidad entre padres y profesores en la educación de niños y jóvenes, si bien es verdad que, asemejándonos a Penélope con más frecuencia de la deseada, el empeño de muchas familias y escuelas puede irse al traste debido a otros influjos e impactos sobre niños y niñas.

Pero no debe olvidársenos una llamada a favor de mayores compromisos institucionales. Educar para la ciudadanía tiene que suponer una estructuración de los centros y de la vida en las aulas con procesos en los que participar en la gestión resolutiva de los problemas que conlleva la vida en común contribuya a crear los correspondientes hábitos y virtudes cívicas, con acciones paralelas en la familia y en la comunidad. Lo cual sólo se podrá hacer con proyectos educativos menos burocráticos.

A todos nos interesa que la Educación para la Ciudadanía funcione, pedagógica y socialmente hablando, y no sólo en los términos de una bondadosa interpretación de su enjundia moral, sino también desde los más conspicuos supuestos del aprendizaje y de la optimización de las condiciones de vida que definen el bienestar de los individuos y de los pueblos. Puede que la escuela tenga servido para legitimar la reproducción social, pero reconozcamos también que conforma uno de los pocos espacios en los que es posible mantener la ficción de la igualdad (cfr. Morán, 2007), en los que es factible garantizar derechos cívicos y, en consecuencia, desarrollar prácticas de ciudadanía efectiva.

\section{DESCRIPCIÓN DEL INSTRUMENTO}

Lo que pretendemos con el instrumento que hemos diseñado no es otra cosa que acercarnos a las actitudes y percepciones del profesorado de Enseñanza Primaria y Secundaria en nuestro país, considerando la reciente implantación de la nueva materia de "Educación para la Ciudadanía y los Derechos Humanos". Con este acercamiento intentamos estimar y calibrar el impacto que el desarrollo de esta materia puede tener sobre un colectivo tan importante, social y educativamente hablando, incluso para la consolidación de la misma a nivel curricular. Nos anima también el deseo de identificar algunas de las claves que pueden facilitar su presencia y desarrollo dentro del sistema educativo.

La construcción del cuestionario que aquí interesa siguió las pautas básicas recomendadas en los textos especializados (Mucchielli, 1974; Selltiz, Wrightsman y 
Cook, 1980; Morales, 1988; Azofra, 2000). Así, a la hora de tomar decisiones sobre el tipo de información que necesitábamos, comenzamos por lo que se denominan "informes de hechos", centrándonos en datos sobre las personas encuestadas, e interesándonos, fundamentalmente, por su historia profesional. De igual forma, también precisábamos información subjetiva, expresada en términos evaluativos, sobre aspectos cuyo conocimiento nos constaba por parte de quienes habían de responder a la encuesta.

De ese modo, y continuando con el mismo esquema que habremos de emplear más adelante en el proceso de validación, dividiremos el cuestionario en tres partes, dependiendo del tipo de información solicitada y del formato de respuesta elegido (en el Apéndice I de este trabajo exponemos el instrumento original, tal y como se presentó en su momento al profesorado):

a) Información sociodemográfica: en el terreno personal, edad y sexo, mientras que en el meramente profesional, se requería titulación, años de experiencia, materia con mayor carga docente para los de Educación Secundaria Obligatoria (ESO), nivel o niveles en los que se enseña y adscripciones de los profesores de Primaria a distintos puestos. Incluimos, finalmente, una serie de aspectos relacionados con el centro de enseñanza, y ahí estarían la titularidad del mismo y las enseñanzas impartidas (ítems del 25 al 33).

b) Información opinativa: en términos estadísticos, se expresa en una serie de ítems de carácter discontinuo (variables categóricas). Abarca cuestiones vinculadas con el sentido humano de la ciudadanía y las instituciones que mejor pueden desarrollarla (ítems 1, 3 y 4) y con la información que tiene actualmente el profesorado sobre la materia en cuestión (ítems del 5 al 13; 15-16; del 19 al 20; y 22-23). Se juntan aquí aspectos como la docencia de esta materia, su evaluación, los recursos necesarios para poder impartirla, el profesorado más adecuado, sus riesgos, sus aspectos polémicos y, por supuesto, las líneas marcadas por el Ministerio de Educación en torno a ella.

c) Información evaluativa: en este caso, y también en términos estadísticos, los ítems son de carácter continuo (expresados en formato de respuesta tipo Likert, donde cada una de las cinco alternativas tiene varias opciones cuantitativas). Todos ellos demandan al profesorado que valore cuáles son los aprendizajes básicos para llegar a ser un buen ciudadano (ítem 2), que refleje su acuerdo o desacuerdo con aspectos relacionados con la enseñanza de esta materia en la escuela (ítem 14), que cuantifique la importancia que concede a una serie de temas relacionados con la disciplina en cuestión (ítem 17), que exprese su acuerdo o desacuerdo con respecto a los objetivos que debe establecer esta materia para ser efectiva (ítem 18), que describa cuantitativamente la frecuencia con que el profesorado realiza en sus clases una serie de actividades relacionadas 
con la docencia (ítem 21) y, finalmente, que calibre, también en términos de acuerdo o desacuerdo, aquellos aspectos relacionados con la formación que el profesorado necesitaría para garantizar una docencia de calidad (item 24).

A fin de poder constatar la calidad técnica de los ítems, seleccionamos a ocho profesores y profesoras universitarias de las Facultades de Ciencias de la Educación y de Psicología y les pedimos que nos contestaran a cinco preguntas. Tres de ellas suponían el análisis y la valoración de cada uno de los ítems por separado:

- ¿En qué medida considera Vd. que cada una de las preguntas de este cuestionario está correctamente planteada? Las opciones de respuesta iban desde "Nada" (1) a "Totalmente" (5) y la respuesta media fue de 4,401 (DT = 3996), lo cual equivale a una valoración de "Mucho", que se puede considerar con una muy alta unanimidad dado su Cociente de Variación (9,0797).

- ¿Le parecen claras las preguntas formuladas en este cuestionario? Las alternativas de respuesta eran semejantes a la cuestión anterior, con lo cual la respuesta que se obtuvo fue también similar (Media $=4,354 ;$ DT =,6228; Cociente de Variación = 14,3041).

- ¿Le parecen inteligibles las preguntas formuladas en este cuestionario? Tanto las respuestas como las valoraciones realizadas se acercaron más a la opción "Totalmente" con una alta unanimidad (Media = 4,687; DT $=, 5554$ y Cociente de Variación $=11,8498)$.

De igual modo, incluimos dos cuestiones referidas a la totalidad del instrumento en los siguientes términos:

- ¿Considera Vd. que las preguntas formuladas en este cuestionario son las adecuadas para los objetivos que se pretenden medir? Las opciones de respuesta oscilaban entre "Nada" (1) y "Totalmente" (5). La consideración de los expertos fue, con elevada unanimidad, de "Mucho" (Media = 4,250; DT $=$,4629; Cociente de Variación = 10,8917).

- ¿Considera Vd. que las preguntas formuladas en este cuestionario abarcan todos los aspectos del fenómeno que se pretende medir? De igual formato que la anterior, la respuesta registrada sigue siendo unánime (aunque algo atenuada) y establecida en torno a la consideración de "Mucho" $($ Media $=4,000 ;$ DT $=$,5345; Cociente Variación $=13,3625)$.

Finalmente, confeccionamos un instrumento con 34 ítems, que sometimos a evaluación con los criterios que pasamos a exponer en el punto siguiente. 


\section{Metodología de VAlidación del Cuestionario}

A pesar de la variedad de tratamientos estadísticos a los que nos vimos abocados dado el carácter continuo y discontinuo de las preguntas diseñadas, conseguimos establecer, con una muestra adecuada, unos criterios de fiabilidad y unos parámetros muy satisfactorios sobre el potencial discriminante del instrumento y la solidez del constructo analizado. Como ya hemos señalado, diferenciaremos los análisis según corresponda a un modelo de variable u otro aclarando, en primer lugar, el procedimiento seguido en la administración de la prueba.

\subsection{Muestreo y procedimiento}

El universo de referencia estuvo compuesto por todos los profesores y profesoras de enseñanza básica (Educación Primaria y Secundaria Obligatoria) que desarrollan su labor profesional en centros, tanto de titularidad pública como privada, de la Comunidad Autónoma de Galicia.

En cuanto a la determinación de la muestra, empleamos un muestreo polietápico, por conglomerados, para la selección de las unidades de primer nivel (en este caso los centros donde llevar a cabo las entrevistas) y por cuotas, de manera proporcional a la distribución de la población según la provincia, nivel de enseñanza (Primaria o Secundaria) y titularidad del centro (público o privado), para la selección de las unidades de segundo nivel (individuos).

Finalmente, administramos el cuestionario a una muestra de 796 profesores ${ }^{2}$ (467 mujeres y 298 varones) con una edad media de 44,6 años oscilando entre 21 y 69 años $(\mathrm{DT}=10,00)$, de centros públicos $(79,2 \%)$, privados $(5,2 \%)$ y privados concertados (15,6\%). Su docencia se distribuye entre Educación Primaria (40,2\%), Educación Secundaria Obligatoria (56,8\%) o bien en ambos niveles (3\%). La experiencia de estos docentes en la enseñanza fluctúa, para el 38\%, entre los 5 y 15 años, un porcentaje menor (30,5\%) lleva trabajando como docente entre 16 y 25 años, y un 31,5\% cuenta con más de 25 años de experiencia. Con respecto al alcance académico de sus titulaciones, un 55,4\% son licenciados y el restante $44,6 \%$ diplomados. La distribución disciplinar de esas mismas titulaciones es como sigue: las del $17 \%$ de los docentes pertenecen a la gran área de conocimiento de Tecnología, las del 35,5\% a la de Humanidades, las del $50,6 \%$ a la de Ciencias Jurídicas y Sociales, y las del 12,2\% a la de las llamadas Ciencias Experimentales.

Los datos fueron recogidos mediante entrevista personal en los propios centros de enseñanza en mayo de 2007. La duración media de las entrevistas se

2. Hipótesis peor: $\mathrm{p}=\mathrm{q}=0,50$; error máximo deseado a nivel global: $\pm 3,48 \%$; nivel de significación: $\alpha=0,05$. 
situó en torno a los 28 minutos. Lo único a señalar, como incidencia importante, fue la eliminación de 31 cuestionarios debido a que presentaban un número excesivo de respuestas en blanco; así, la muestra acabó siendo de 765 profesores y profesoras.

\subsection{Variables sociodemográficas}

Con la información que aportan estas variables, hemos constatado su capacidad discriminatoria y predictiva (Kerlinger, 1987; Muñiz, 2001) sobre las variables que constituyen el contenido propiamente dicho del instrumento propuesto.

TABla 1. Número de Veces Que Cada VARIable SOCIODEMOGRÁfica PRESENTA DIFERENCIAS SIGNIFICATIVAS EN VARIABLES DE CONTENIDO $(\mathrm{N}=23)$

\begin{tabular}{|c|c|c|c|}
\hline Variable sociodemográfica & $\mathrm{f}$ & $\%$ & \multicolumn{1}{c|}{ Variables dependientes } \\
\hline Sexo & 5 & 21,74 & $\begin{array}{l}\text { - Aprender Ciudadanía (2). Instituciones (3). Líneas } \\
\text { concretas (8). Programas Comunitarios (4). } \\
\text { Evaluación (19). }\end{array}$ \\
\hline Provincia & 5 & 21,74 & $\begin{array}{l}\text { - Aprender Ciudadanía (2). Instituciones (3). Programas } \\
\text { Comunitarios (4). Decisión (6). Polémica (15). }\end{array}$ \\
\hline Experiencia & 7 & 34,43 & $\begin{array}{l}\text { - Aprender Ciudadanía (2). Líneas concretas } \\
\text { (8). Decisión (6). Evaluación (19). } \\
\text { Programas Comunitarios (4). Cómo enseñar } \\
\text { (7). Innovación Educativa (13). }\end{array}$ \\
\hline Nivel en el que se enseña & 7 & 34,43 & $\begin{array}{l}\text { - Sentido de Ciudadanía (1). Aprender Ciudadanía } \\
\text { (2). Instituciones (3). Información (5). Decisión } \\
\text { (6). Utilidad y Conflicto (14). Polémica (15). }\end{array}$ \\
\hline Grado de la titulación & 5 & 21,74 & $\begin{array}{l}\text { Aprender Ciudadanía (2). } \\
\text { Aprender Ciudadanía (2). Instituciones } \\
\text { (3). Información (5). Utilidad y } \\
\text { Conflicto (14). Polémica (15). }\end{array}$ \\
\hline Mayor carga docente & 5 & 21,74 & $\begin{array}{l}\text { - Aprender Ciudadanía (2). Instituciones (3). Programas } \\
\text { Comunitarios (4). Decisión (6). Líneas concretas (8). }\end{array}$ \\
\hline
\end{tabular}

En el primer caso (ver Tabla 1) queríamos establecer las diferencias significativas entre los distintos grupos que configuran cada una de las variables sociodemográficas y, a ese efecto, aplicamos para los ítems categóricos (1, 3, 4, $5,6,7,8,13,15$ y 19) la prueba de Chi-Cuadrado, y para los continuos la "t" de Student cuando eran dos grupos y el Anova de 1 factor cuando eran más de dos grupos (Bisquerra, 1987). 
Las que mejor discriminan, según estos análisis, son la titulación que se posee (Ciencias Experimentales, Jurídicas y Sociales, Humanidades y Tecnología), el nivel en el que se enseña (Primaria y/o Secundaria Obligatoria) y los años de experiencia en la enseñanza. Le siguen en importancia el sexo, la provincia, el grado de su titulación (licenciado o diplomado) y, en el caso de la ESO, la materia en la que se tiene la mayor carga docente.

Para analizar su capacidad predictiva (ver Tabla 2) aplicamos el análisis de regresión lineal "de pasos sucesivos" utilizando como variables independientes aquellas que consideramos sociodemográficas y, como dependientes, las que configuran el contenido del cuestionario. Además de su valor predictivo, también nos interesaba conocer el grado de dependencia que tienen las opiniones y valoraciones del profesorado sobre esta materia con respecto a su perfil profesional (Hair, Anderson, Tatham y Black, 1999).

Como se podrá apreciar, la experiencia (hasta cinco años el 15\%, entre seis y quince años el 23,3\%, entre dieciséis y veinticinco el 30,6\%, y con más de veinticinco años el 31,1\%), área a la que pertenece su titulación (12,2\% Ciencias Experimentales, 50,6\% Ciencias Jurídicas y Sociales, 35,5\% Humanidades y 1,7\% Técnicas) y el sexo, son las que establecen esta relación de dependencia con más peso. Entendemos, finalmente, que la titularidad del centro ha de ser considerada dada la importancia de sus relaciones con la docencia, la evaluación, los contenidos y la formación del profesorado en Educación para la Ciudadanía.

TABLA 2. N. ${ }^{\circ}$ DE VECES QUE CADA VARIABLE SOCIODEMOGRÁFicA APARECE COMO PREDICTORA DE VARIABLES DE CONTENIDOS CON LOS RESPECTIVOS ÍNDICES DEL MODELO DE REGRESIÓN

\begin{tabular}{|c|c|c|c|c|c|c|c|c|}
\hline $\mathrm{VI}_{1}$ & $\mathrm{R}$ & $\mathrm{R}^{2}$ & $\mathrm{R}^{2} \mathrm{C}$ & P & $\mathrm{F}$ & Sig. & Otras $\mathrm{VI}_{1}$ & $\mathrm{VD}_{1}(\mathrm{~N}=23)$ \\
\hline \multirow{8}{*}{$\begin{array}{c}\text { Titulación } \\
(\mathrm{n}=8 ; 36,36 \%)\end{array}$} & , 192 & ,037 &, 032 & ,119 & 7,260 & ,001 & Sexo & $\begin{array}{c}\text { Sentido de } \\
\text { Ciudadanía (1) }\end{array}$ \\
\hline & , 185 & ,034 & ,027 & ,103 & 4,484 & ,004 & $\begin{array}{l}\text { Grado } \\
\text { Sexo }\end{array}$ & Instituciones (3) \\
\hline & , 183 & 033 & ,028 & , 106 & 6,311 &, 002 & Provincia & Decisión (6) \\
\hline & , 151 &, 023 &, 020 &,- 151 & 8,843 &, 003 & - & Cómo enseñar (7) \\
\hline & , 198 & ,039 &, 037 &,- 198 & 15,489 &, 000 & - & Innovación (13) \\
\hline & ,132 &, 017 &, 015 & ,132 & 6,667 & ,010 & - & $\begin{array}{c}\text { Utilidad y } \\
\text { Conflicto (14) }\end{array}$ \\
\hline & ,233 &, 054 &, 047 &,- 120 & 7,250 & ,000 & $\begin{array}{c}\text { Materia mayor } \\
\text { carga docente, } \\
\text { Experiencia }\end{array}$ & Importancia (17) \\
\hline & , 195 & ,038 &, 030 &,- 102 & 4,977 &, 002 & $\begin{array}{c}\text { Grado } \\
\text { Nivel } \\
\text { educativo en } \\
\text { el que enseña }\end{array}$ & $\begin{array}{l}\text { Actividad } \\
\text { diaria }(21)\end{array}$ \\
\hline
\end{tabular}



¿QUÉ ES LO QUE IMPORTA EN EDUCACIÓN PARA LA CIUDADANÍA?

\begin{tabular}{|c|c|c|c|c|c|c|c|c|}
\hline $\mathrm{VI}_{1}$ & $\mathrm{R}$ & $\mathrm{R}^{2}$ & $\mathrm{R}^{2} \mathrm{C}$ & $\mathrm{P}$ & $\mathrm{F}$ & Sig. & Otras $\mathrm{VI}_{1}$ & $\mathrm{VD}_{1}(\mathrm{~N}=23)$ \\
\hline \multirow{11}{*}{$\begin{array}{c}\text { Experiencia } \\
(\mathrm{n}=11 ; 50 \%)\end{array}$} & , 134 & ,018 &, 015 &,- 134 & 6,746 &, 010 & - & $\begin{array}{c}\text { Sentido de } \\
\text { Ciudadanía (1) }\end{array}$ \\
\hline &, 217 &, 047 &, 042 &,- 121 & 9,390 &, 000 & Provincia & Instituciones (3) \\
\hline &, 111 & ,012 &, 010 &,- 111 & 4,732 & ,030 & - & $\begin{array}{c}\text { Utilidad y } \\
\text { Conflicto (14) }\end{array}$ \\
\hline &, 170 &, 029 &, 024 &,- 100 & 5,652 &, 004 & $\begin{array}{l}\text { Materia mayor } \\
\text { carga docente }\end{array}$ & $\begin{array}{c}\text { Formación } \\
(23 / 24) \\
\end{array}$ \\
\hline & 157 &, 025 & 022 &,- 157 & 9,593 & ,002 & - & Polémica (15) \\
\hline &, 233 &, 054 &, 049 &,- 102 & 10,894 &, 000 & Sexo & Importancia (17) \\
\hline & , 197 & ,039 &, 031 & , 103 & 5,092 &, 002 & $\begin{array}{l}\text { Sexo } \\
\text { Grado }\end{array}$ & Evaluación (19) \\
\hline & ,121 & 015 & 012 &, 121 & 5,305 & 022 & -- & Calidad (20) \\
\hline &, 180 & ,032 &, 027 & ,115 & 6,343 & ,002 & $\begin{array}{l}\text { Titularidad } \\
\text { del Centro }\end{array}$ & $\begin{array}{c}\text { Docencia } \\
\text { cotidiana (21) } \\
\end{array}$ \\
\hline & , 153 &, 023 &, 018 & ,101 & 4,556 & 011 & Titulación & Efectividad (18) \\
\hline & ,162 &, 026 &, 021 &,- 102 & 5,116 & ,006 & Sexo & $\begin{array}{c}\text { Aprender } \\
\text { Ciudadanía (2) }\end{array}$ \\
\hline \multirow{3}{*}{$\begin{array}{c}\text { Provincia } \\
(\mathrm{n}=3 ; 13,04 \%)\end{array}$} &, 115 &, 013 &,- 011 &,- 115 & 5,138 &, 024 & - & Instituciones (3) \\
\hline &, 171 &, 029 &, 024 &, 110 & 5,686 & 004 & Sexo & Importancia (17) \\
\hline &, 101 & ,010 &, 008 &, 101 & 3,960 & ,047 & -- & $\begin{array}{c}\text { Aprender } \\
\text { Ciudadanía (2) }\end{array}$ \\
\hline \multirow{2}{*}{$\begin{array}{l}\text { Materia mayor } \\
\text { carga docente } \\
(\mathrm{n}=2 ; 8,69 \%)\end{array}$} &, 105 & 011 & ,009 &,- 105 & 4,284 & 039 & -- & Importancia (17) \\
\hline & ,105 &, 011 &, 008 &,- 105 & 4,258 &, 040 & -- & $\begin{array}{c}\text { Aprender } \\
\text { Ciudadanía (2) }\end{array}$ \\
\hline \multirow{2}{*}{$\begin{array}{l}\text { Nivel educativo } \\
\text { en el que enseña } \\
(\mathrm{n}=2 ; 8,69 \%)\end{array}$} & , 163 & ,026 &, 024 &, 163 & 10,353 &, 001 & -- & $\begin{array}{c}\text { Docencia } \\
\text { cotidiana }(21)\end{array}$ \\
\hline &, 111 & ,012 &, 010 &, 111 & 4,759 & ,039 & -- & $\begin{array}{c}\text { Aprender } \\
\text { Ciudadanía (2) }\end{array}$ \\
\hline $\begin{array}{c}\text { Grado } \\
(\mathrm{n}=1 ; 4,35 \%)\end{array}$ &, 162 & ,026 &, 021 & ,101 & 5,100 &, 007 & Titulación & $\begin{array}{c}\text { Aprender } \\
\text { Ciudadanía (2) }\end{array}$ \\
\hline \multirow{7}{*}{$\begin{array}{c}\text { Sexo } \\
(\mathrm{n}=7 ; 30,43 \%)\end{array}$} &, 110 & ,012 &, 010 &, 110 & 4,698 & ,031 & - & $\begin{array}{c}\text { Líneas } \\
\text { concretas (8) }\end{array}$ \\
\hline &, 240 &, 057 &, 052 & ,162 & 11,525 &, 000 & $\begin{array}{l}\text { Titularidad } \\
\text { del Centro }\end{array}$ & Importancia (17) \\
\hline &, 540 & 292 & ,266 &, 540 & 11,522 &, 002 & - & Instituciones (3) \\
\hline & , 171 & ,029 & 027 &,- 171 & 11,366 & 001 & - & Calidad (20) \\
\hline & , 104 &, 011 &, 008 &, 104 & 4,054 &, 042 & - & $\begin{array}{c}\text { Docencia } \\
\text { cotidiana (21) } \\
\end{array}$ \\
\hline & ,164 &, 027 &, 022 &, 113 & 5,204 & ,006 & Titulación & Efectividad (18) \\
\hline &, 113 &, 013 &, 010 &, 113 & 4,900 &, 027 & - & $\begin{array}{c}\text { Aprender } \\
\text { Ciudadanía (2) }\end{array}$ \\
\hline
\end{tabular}



¿QUÉ ES LO QUE IMPORTA EN EDUCACIÓN PARA LA CIUDADANÍA?

\begin{tabular}{|c|c|c|c|c|c|c|c|c|}
\hline $\mathrm{VI}_{1}$ & $\mathrm{R}$ & $\mathrm{R}^{2}$ & $\mathrm{R}^{2} \mathrm{C}$ & $\mathrm{P}$ & $\mathrm{F}$ & $\mathrm{Sig}$. & Otras $\mathrm{VI}_{1}$ & $\mathrm{VD}_{1}(\mathrm{~N}=23)$ \\
\hline \multirow{4}{*}{$\begin{array}{c}\text { Titularidad } \\
\text { del Centro } \\
(\mathrm{n}=4 ; 17,39 \%)\end{array}$} &, 173 &, 030 &, 025 &,- 113 & 5,888 &, 003 & Grado & Evaluación (19) \\
\cline { 2 - 9 } &, 200 &, 040 &, 035 &, 114 & 7,885 &, 000 & Grado & $\begin{array}{c}\text { Docencia } \\
\text { cotidiana (21) }\end{array}$ \\
\cline { 2 - 9 } &, 210 &, 044 &, 009 &, 108 & 4,464 &, 035 & - & $\begin{array}{c}\text { Aprender } \\
\text { Ciudadanía (2) }\end{array}$ \\
\cline { 2 - 8 } & &, 122 & 8,707 &, 000 & Grado & $\begin{array}{c}\text { Formación } \\
(23 / 24)\end{array}$ \\
\hline
\end{tabular}

\subsection{Variables categóricas}

Dado su carácter opinativo y nuestra necesidad de abarcar, con la mayor extensión posible, aquellos temas que representan el contexto de la EpC, no era esperable una fuerte consistencia en su estructura $\mathrm{o}$, mejor dicho, una fuerte asociación entre todos los temas ahora considerados. De todas formas, tal comprobación (ver Tabla 3) se hizo empleando la correlación Rho de Spearman (Bisquerra, 1987; Siegel y Castellan, 1995), lo cual permitió constatar algunas regularidades.

Tabla 3. Índices de Calidad y VAlidez estructural De los Ítems Categóricos y nominales (Rho de Spearman)

\begin{tabular}{|c|c|c|c|}
\hline ÍTEM & $\begin{array}{c}\text { Correlación media del ítem } \\
\text { (todas las variables) }\end{array}$ & $\begin{array}{c}\text { Correlación media del ítem } \\
\text { (sólo Rho significativas) }\end{array}$ & Nombre del ítem \\
\hline 1 &, 023 &, $085(3,85 \%)$ & Sentido de la ciudadanía \\
\hline 3 &, 036 &, $059(20,15 \%)$ & Instituciones \\
\hline 4 &, 085 &, $173(18,52 \%)$ & Progr. Serv. Comunitarios \\
\hline 5 &, 058 &, $117(14,81 \%)$ & Información \\
\hline 6 &, 140 &, $171(58,82 \%)$ & Decisión \\
\hline 7 &, 096 &, $144(44,44 \%)$ & Cómo enseñar \\
\hline 8 &, 055 &, $143(22,22 \%)$ & Líneas concretas \\
\hline 12 &, 063 &, $115(22,22 \%)$ & Riesgo \\
\hline 13 &, 112 &, $106(18,52 \%)$ & Innovación educativa \\
\hline 15 &, 064 &, $141(21,21 \%)$ & Polémica \\
\hline 19 &, 060 &, $108(23,19 \%)$ & Calidad \\
\hline 20 &, 042 & & \\
\hline
\end{tabular}

Como se puede observar en la Tabla 3, el ítem 6 (considerar si es un acierto o una equivocación introducir esta materia en el currículo), el 7 (cómo se debe enseñar esta materia), el 13 (el hecho de considerarla como fundamental de cara a la innovación educativa de los centros), el 20 (aspectos importantes para impartir la materia con calidad), el 8 (referido al conocimiento existente sobre las líneas del 
Ministerio respecto de esta materia) y el 12 (consideración del riesgo que tiene la inclusión de esta materia en este momento), ofrecen unos porcentajes elevados de correlaciones significativas con las demás variables y una correlación media, que, aun siendo baja, es superior a las demás.

Para analizar su capacidad de discriminación tenemos que observar las Tablas 1, que ya hemos comentado, y 4. La segunda nos indica que, dada su ausencia en ambas tablas, los ítems 12 y 20 deben ser tomados con reservas y, en cambio, el 15 (la consciencia de que la introducción de esta materia es polémica en algunos sectores) y el 19 (la opinión sobre cómo debe ser evaluada) adquieren una relevancia que no tenían al comentar su asociación con el resto (ver Tabla 3), motivo por el cual pueden ser incluidos en la propuesta final del cuestionario.

TABla 4. Niveles de DisCRIMINACIÓN DE LOS ÍTEMS CATEGÓRICOS Y NOMINALES CON LAS TRES VARIABLES SOCIODEMOGRÁFICAS MÁS REPRESENTATIVAS

\begin{tabular}{|c|c|c|c|c|c|c|}
\hline \multicolumn{2}{|c|}{ Variables } & $\mathrm{X}^{2}$ & Sig. & N válidas & $\% \mathrm{fe}<5$ & $\begin{array}{c}\text { Coeficiente } \\
\text { Contigencia }\end{array}$ \\
\hline \multirow{5}{*}{$\begin{array}{c}\text { Nivel de } \\
\text { Enseñanza }\end{array}$} & $\begin{array}{c}\text { Responsabilidad } \\
(1)\end{array}$ & 31,196 &, 027 & 757 & $18,5 \%$ &, $199(, 027)$ \\
\cline { 2 - 7 } & Escuela (3) & 10,159 &, 006 & 765 & $0 \%$ &, $114(, 006)$ \\
\cline { 2 - 7 } & Familia (3) & 23,461 &, 000 & 765 & $16,7 \%$ &, $172(, 000)$ \\
\cline { 2 - 7 } & Información (5) & 10,255 &, 006 & 765 & $16,7 \%$ &, $115(, 006)$ \\
\cline { 2 - 7 } & Decisión (6) & 14,359 &, 026 & 738 & $16,7 \%$ &, $138(, 026)$ \\
\cline { 2 - 7 } & Polémica (15) & 21,772 &, 000 & 765 & $16,7 \%$ &, $166(, 000)$ \\
\hline \multirow{5}{*}{ Experiencia } & $\begin{array}{c}\text { Programas } \\
\text { Comunitarios (4) }\end{array}$ & 15,886 &, 014 & 759 & $0 \%$ &, $143(, 014)$ \\
\cline { 2 - 7 } & Decisión (6) & 29,705 &, 000 & 732 & $0 \%$ &, $197(, 000)$ \\
\cline { 2 - 7 } & Cómo enseñar (7) & 31,350 &, 000 & 751 & $0 \%$ &, $200(, 000)$ \\
\cline { 2 - 7 } & $\begin{array}{c}\text { Líneas } \\
\text { concretas (8) }\end{array}$ & 8,500 &, 037 & 759 & $0 \%$ &, $105(, 037)$ \\
\cline { 2 - 7 } & $\begin{array}{c}\text { Innovación } \\
\text { Educativa (13) }\end{array}$ & 12,297 &, 050 & 759 & $0 \%$ &, $126(, 050)$ \\
\cline { 2 - 7 } & Evaluación (19) & 13,268 &, 004 & 759 & $0 \%$ &, $131(, 004)$ \\
\hline \multirow{5}{*}{ Titulación } & Instituciones (3) & 12,691 &, 005 & 712 & $12,5 \%$ &, $132(, 005)$ \\
\cline { 2 - 7 } & Información (5) & 17,552 &, 001 & 172 & $25 \%$ &, $155(, 001)$ \\
\cline { 2 - 7 } & Decisión (6) & 20,987 &, 013 & 683 & $25 \%$ &, $173(, 013)$ \\
\cline { 2 - 7 } & Cómo enseñar (7) & 39,546 &, 000 & 704 & $18,8 \%$ &, $231(, 000)$ \\
\cline { 2 - 7 } & $\begin{array}{c}\text { Innovación } \\
\text { educativa (13) }\end{array}$ & 35,014 &, 000 & 712 & $25 \%$ &, $216(, 000)$ \\
\cline { 2 - 7 } & Polémica (15) & 11,259 &, 010 & 712 & $12,5 \%$ &, $125(, 010)$ \\
\cline { 2 - 7 } & Evaluación (19) & 15,715 &, 001 & 712 & $12,5 \%$ & $, 001)$ \\
\hline
\end{tabular}




\subsection{Variables continuas}

En este caso se trata de seis variables, con un marcado carácter evaluativo, sobre los mejores aprendizajes para ser un buen ciudadano (ítem 2), la consideración de si tiene sentido enseñar ciudadanía en la escuela (ítem 14), la valoración de los temas que debería incluir esta materia (ítem 17), el posicionamiento en torno a lo que sería una enseñanza efectiva de esta disciplina (ítem 18), la constatación de las actividades más frecuentes que el profesorado realiza en sus clases (ítem 21) y, por último, una valoración sobre la formación necesaria para que el profesorado pueda impartirla con eficacia (ítem 24).

Pensando en la capacidad de discriminación de estos ítems, seleccionamos las tres variables sociodemográficas que más inciden en la diversidad de respuestas de este cuestionario (experiencia en años, titulación que se posee y nivel en el que se enseña) y observamos su potencial diferenciador con estas variables mediante un Anova de 1 factor con contraste Scheffé (Bisquerra, 1987). Como puede apreciarse en la Tabla 5, hemos encontrado 83 cuestiones en las que se aprecian diferencias significativas $(\mathrm{p} \leq, 05)$ en las tres variables sociodemográficas: en la experiencia un 59\% para 35 ítems; en la titulación un 33,9\% para 20 ítems; y en el nivel en el que se enseña, un $47,45 \%$ para 28 ítems (téngase en cuenta que el porcentaje se calcula sobre 59 variables que son las que comprenden los seis ítems a los que nos estamos refiriendo).

Podemos observar que la valoración de los temas que tendría que incluir esta materia (ítem 17), la valoración sobre la efectividad y los aspectos que debe enfatizar la EpC (ítem 18), lo que deben aprender los alumnos para ser buenos ciudadanos (ítem 2) y las actividades más frecuentes que el profesorado realiza en sus clases (ítem 21) son los que más y mejor discriminan, según la experiencia, la titulación y el nivel en el que se enseña.

En cuanto a su calidad técnica (Bisquerra, 1987; Morales, 1988), presentamos en la Tabla 6 los índices que mejor representan esta faceta del instrumento que proponemos. Observándola, apreciamos que lo que deben aprender los alumnos para ser buenos ciudadanos (ítem 2), los temas que debería incluir la EpC (ítem 17) y los factores que, de llevarse a cabo su implantación, convergerían en una enseñanza efectiva y eficaz (ítem 18) son los que presentan unos indicadores satisfactorios, lo que es, básicamente, sinónimo de consistencia. 
AGUSTÍN GODÁS OTERO, MIGUEL A. SANTOS REGO Y MAR LORENZO MOLEDO ¿QUÉ ES LO QUE IMPORTA EN EDUCACIÓN PARA LA CIUDADANÍA?

TABla 5. CAPACIDAD DE DisCRIMINACIÓN DE LOS ÍTEMS CONTINUOS CON LAS VARIABLES SOCIODEMOGRÁFICAS MÁS REPRESENTATIVAS

\begin{tabular}{|c|c|}
\hline Variable independiente & Variables dependientes \\
\hline \multirow{6}{*}{ Experiencia } & Ítem 2: 2.1, 2.6, 2.7, 2.9 a $2.11,2.13,2.14$ \\
\hline & Ítem 14: Ninguna \\
\hline & Ítem 17: $17.2,17.4$ a 17.17 \\
\hline & Ítem 18: 18.1, 18.3, 18.5, 18.7 \\
\hline & Ítem 21: 21.1, 21.2, 21.5, 21.7 \\
\hline & Ítem 24: 24.2, 24.4 \\
\hline \multirow{6}{*}{ Titulación } & Ítem 2: 2.9, 2.11, 2.12 a 2.14 \\
\hline & Ítem 14: 14.1, 14.3 \\
\hline & Ítem 17: 17.1, 17.4, 17.9, 17.13, 17.14, 17.17 \\
\hline & Ítem 18: 18.3, 18.6 \\
\hline & Ítem 21: 21.1, 21.3, 21.5, 21.7 \\
\hline & Ítem 24: 24.3 \\
\hline \multirow{6}{*}{ Nivel de enseñanza } & Ítem 2: 2.8, 2.9, 2.11 a 2.15 \\
\hline & Ítem 14: 14.1 \\
\hline & Ítem 17: $17.4,17.8,17.10$ a $17.14,17.16$ \\
\hline & Ítem 18: 18.1, 18.3, 18.6 \\
\hline & Ítem 21: 21.1, 21.4, 21.5, 21.7, 21.9 \\
\hline & Ítem 24: 24.2 a 24.4 \\
\hline
\end{tabular}

Tabla 6. Índices REPRESENTATIVOS de la CALIDAD téCNICA DE LOS ÍTEMS CONSIDERADOS como variables continuas ( $\alpha$ de Cronbach, media, desviación típica, COEFICIENTES DE HOMOGENEIDAD Y VARIACIÓN)

\begin{tabular}{|c|c|c|c|c|c|c|}
\hline Ítems & $\begin{array}{c}\alpha \text { Media } \\
\text { del ítem }\end{array}$ & $\begin{array}{c}\text { Correlación } \\
\text { media entre } \\
\text { ítems }\end{array}$ & Media & DT & $\begin{array}{c}\text { Coeficiente de } \\
\text { Homogeneidad }\end{array}$ & $\begin{array}{c}\text { Coeficiente } \\
\text { de Variación }\end{array}$ \\
\hline $\begin{array}{c}\text { Aprender } \\
\text { Ciudadanía (2) }\end{array}$ &, 778 &, 211 & 6,615 & 2,133 &, 40 & $32,24 \%$ \\
\hline $\begin{array}{c}\text { Utilidad y } \\
\text { Conflicto (14) }\end{array}$ &, 544 &, 287 & 3,526 & 3,018 &, 36 & $85,59 \%$ \\
\hline $\begin{array}{c}\text { Importancia } \\
(17)\end{array}$ &, 907 &, 384 & 7,566 & 2,073 &, 59 & $27,40 \%$ \\
\hline \begin{tabular}{c} 
Efectividad (18) \\
\hline $\begin{array}{c}\text { Docencia } \\
\text { cotidiana (21) }\end{array}$
\end{tabular} &, 854 &, 469 & 7,116 & 2,101 &, 62 & $29,52 \%$ \\
\hline $\begin{array}{c}\text { Formación } \\
(24 / 23)\end{array}$ &, 777 &, 160 & 5,447 & 2,753 &, 31 & $50,54 \%$ \\
\hline
\end{tabular}


Tabla 7. Análisis estructural de las variables continuas (COMPONENTES PRINCIPALES CON ROTACIÓN. VARIANZAS)

\begin{tabular}{|c|c|c|c|c|}
\hline Factor & Autovalor & $\%$ Varianza & Ítems & Peso \\
\hline \multirow{18}{*}{$\begin{array}{c}\text { I } \\
\text { Contenidos }\end{array}$} & \multirow{18}{*}{8,299} & \multirow{18}{*}{14,820} & Importancia (Minorías culturales) (17.12) &, 735 \\
\hline & & & Importancia (Igualdad) (17.11) &, 714 \\
\hline & & & Importancia (Medio Ambiente) (17.13) & 690 \\
\hline & & & Importancia (Inmigración) (17.7) & ,682 \\
\hline & & & Importancia (Globalización) (17.17) & ,628 \\
\hline & & & Importancia (Bienestar social) (17.10) &, 589 \\
\hline & & & Importancia (Conflictos) (17.9) & ,589 \\
\hline & & & Aprender Ciudadanía (Medio Ambiente) (2.13) & ,583 \\
\hline & & & Importancia (Competencias Cívicas) (17.15) &, 574 \\
\hline & & & Importancia (Derechos y Deberes) (17.2) &, 571 \\
\hline & & & Importancia (Organizaciones) (17.6) &, 567 \\
\hline & & & Importancia (Tipos de familia) (17.16) &, 565 \\
\hline & & & Aprender Ciudadanía (Derechos) (2.11) &, 508 \\
\hline & & & Importancia (Historia) (17.8) & 488 \\
\hline & & & Importancia (Democracia) (17.3) & 480 \\
\hline & & & Aprender Ciudadanía (Injusticia) (2.5) &, 426 \\
\hline & & & Importancia (Propaganda) (17.14) & 420 \\
\hline & & & Aprender Ciudadanía (Altruismo) (2.9) &, 405 \\
\hline \multirow{10}{*}{$\begin{array}{c}\text { II } \\
\text { Objetivos }\end{array}$} & \multirow{10}{*}{4,600} & \multirow{10}{*}{8,214} & Efectividad (Aprender a cooperar) (18.1) & ,648 \\
\hline & & & Efectividad (Resolver problemas) (18.3) & ,614 \\
\hline & & & Formación (Materia obligatoria) (24/23.3) & ,613 \\
\hline & & & Formación (Asesorías) (24/23.4) & 609 \\
\hline & & & Formación (Imagen social profesorado) (24/23.5) & ,587 \\
\hline & & & Formación (Plan específico) $(24 / 23.2)$ & ,568 \\
\hline & & & Efectividad (Pensamiento crítico) (18.4) & ,524 \\
\hline & & & Efectividad (Conocer a la sociedad) (18.5) &, 520 \\
\hline & & & Efectividad (Valores democráticos) (18.7) &, 504 \\
\hline & & & Utilidad y Conflicto (Consenso utilidad) (14.1) & 404 \\
\hline \multirow{7}{*}{$\begin{array}{c}\text { III } \\
\text { Contenidos } \\
\text { y objetivos }\end{array}$} & \multirow{7}{*}{3,848} & \multirow{7}{*}{6,871} & Aprender Ciudadanía (Implicarse en debate) (2.12) & ,626 \\
\hline & & & Aprender Ciudadanía (Interés político) (2.8) & ,613 \\
\hline & & & Efectividad (Estructuras del gobierno) (18.2) &, 554 \\
\hline & & & Importancia (Sistema electoral) (17.4) &, 549 \\
\hline & & & Importancia (Constitución y Estatutos) (17.1) &, 525 \\
\hline & & & $\begin{array}{l}\text { Efectividad (Participación política } \\
\text { y comunitaria) (18.6) }\end{array}$ &, 520 \\
\hline & & & Aprender Ciudadanía (Afiliación) (2.3) & ,482 \\
\hline
\end{tabular}


¿QUÉ ES LO QUE IMPORTA EN EDUCACIÓN PARA LA CIUDADANÍA?

\begin{tabular}{|c|c|c|c|c|}
\hline Factor & Autovalor & $\%$ Varianza & Ítems & Peso \\
\hline \multirow{5}{*}{$\begin{array}{c}\text { IV } \\
\text { Docencia }\end{array}$} & \multirow{5}{*}{2,736} & \multirow{5}{*}{4,886} & Docencia cotidiana (Debates polémicos) (21.8) & ,622 \\
\hline & & & Docencia cotidiana (Trabajo en grupo) (21.4) &, 602 \\
\hline & & & Docencia cotidiana (Proyectos fuera del aula) (21.1) &, 578 \\
\hline & & & $\begin{array}{l}\text { Docencia cotidiana (Participación } \\
\text { comunitaria) (21.9) }\end{array}$ &, 564 \\
\hline & & & Docencia cotidiana (Simulaciones) (21.7) &, 523 \\
\hline \multirow{7}{*}{$\begin{array}{c}\text { V } \\
\text { Ciudadanía }\end{array}$} & \multirow{7}{*}{2,585} & \multirow{7}{*}{4,616} & Aprender Ciudadanía (Ser patriota) (2.14) &, 676 \\
\hline & & & Aprender Ciudadanía (Obedecer ley) (2.1) &, 581 \\
\hline & & & Aprender Ciudadanía (Dispuesto a alistarse) (2.7) &, 525 \\
\hline & & & Aprender Ciudadanía (Trabajar duro) (2.4) & ,486 \\
\hline & & & $\begin{array}{l}\text { Aprender Ciudadanía (Respecto } \\
\text { a representantes) (2.10) }\end{array}$ & ,461 \\
\hline & & & Aprender Ciudadanía (Votar) (2.2) & ,387 \\
\hline & & & Docencia cotidiana (Libros de texto) (21.2) & ,334 \\
\hline \multicolumn{5}{|c|}{ TOTAL = 39,406 } \\
\hline
\end{tabular}

Esa afirmación se ve reforzada cuando se realiza un análisis estructural del constructo que representan dichos ítems (ver Tabla 7). Por medio de un análisis factorial de componentes principales con rotación Varimax, hemos constatado que lo más representativo atañe a los temas de contenido de la EpC, a la eficacia de la propia materia en relación con las repercusiones que debería tener su enseñanza en los estudiantes (aprendizajes, valores, actitudes, participación y conocimiento social, fundamentalmente), a los aprendizajes básicos para llegar a ser un buen ciudadano y a las actividades que más abundan en las clases de los docentes.

El ítem 14, que hace referencia a la valoración sobre la necesidad o el sentido que tiene introducir una materia de este tipo en el currículo, queda totalmente fuera del constructo que reflejan el resto de las cuestiones. En cambio, el que hace hincapié en las necesidades de formación del profesorado para afrontar en condiciones su docencia (ítem 24), aparece fuertemente constreñido en el factor II, al lado de las repercusiones que tendrá esta materia en la vida social del alumnado que la curse (actitudes, valores, participación y conocimiento social), motivo por el cual su consideración debe ser tenida en cuenta dentro del constructo.

\section{Conclusiones}

Lo primero que hemos podido constatar en la realización del presente estudio es la escasez de instrumentos (cuestionarios, escalas...) y de publicaciones al respecto, planteando la compleja cuestión de cómo medir opiniones y valoraciones del profesorado en relación con la Educación para la Ciudadanía y los Derechos Humanos. De hecho, el referente más destacado siguen siendo los estudios de Torney-Purta y su equipo $(1999,2001)$ en el tránsito del viejo al nuevo siglo. 
Desde entonces, apenas contamos con investigaciones que nos permitan discernir los aspectos básicos (objetivos, contenidos, metodología aplicada, evaluación...) de un currículo que debe servir para que niños y jóvenes crezcan en dominio de destrezas cívicas. Afortunadamente, la IEA ha comenzado los preparativos del nuevo estudio, cuyo inicio está previsto para el año 2009, pero cuyos resultados no se conocerán antes de septiembre del 2010.

Justamente, en este artículo lo que hemos pretendido es presentar un instrumento que nos permite conocer las actitudes y percepciones del profesorado de Enseñanza Primaria y Secundaria hacia la materia de "Educación para la Ciudadanía y los Derechos Humanos". Pero además de su presentación, explicamos el procedimiento de su diseño y validación.

Para su construcción seguimos las pautas básicas recomendadas en los textos especializados. De ese modo, diseñamos un cuestionario de 34 ítems que dependiendo del tipo de información solicitada y del formato de respuesta elegido agrupamos en tres partes.

Una primera, de Información sociodemográfica ( 9 ítems), tanto personal (edad y sexo), profesional (titulación, años de experiencia, materia con mayor carga docente -ESO-, nivel o niveles en los que se enseña y adscripciones de los profesores de Primaria a distintos puestos) como del propio centro de enseñanza (titularidad y enseñanzas impartidas). Una segunda, que recoge Información opinativa, con variables categóricas que abarcan cuestiones vinculadas con el sentido humano de la ciudadanía y las instituciones que mejor pueden desarrollarla (3 ítems) y con la información que tienen los docentes sobre la materia (15 ítems). Y, por último, Información evaluativa, con ítems de carácter continuo (formato de respuesta tipo Likert) en los que se pide valoración al profesorado sobre cuáles son los aprendizajes básicos para llegar a ser un buen ciudadano, su acuerdo o desacuerdo con aspectos relacionados con la enseñanza de esta materia en la escuela, con la formación que el profesorado necesitaría para garantizar una docencia de calidad y con los objetivos que debe establecer para ser efectiva, importancia que se concede a una serie de temas relacionados con la disciplina y frecuencia con la que realizan en sus clases una serie de actividades docentes.

Sin embargo, todo instrumento debe ser sometido a pruebas de evaluación (calidad técnica de los ítems, fiabilidad, tipos de validez y análisis psicométrico de los ítems).

La evaluación del cuestionario presentado en este artículo nos permite destacar los siguientes aspectos:

- En función de las valoraciones hechas por los 8 jueces expertos sobre la calidad técnica de los ítems, puede afirmarse que las cuestiones formuladas son claras, comprensibles y están correctamente planteadas. De igual forma, los temas incluidos son los adecuados a la temática objeto de investigación y, en menor medida (aunque con una alta consideración), se entiende que el instrumento es suficientemente exhaustivo y abarca lo más sustantivo de la materia de Educación para la Ciudadanía. 
- Centrándonos ya en la validación de los tres grandes grupos de variables del cuestionario, destacamos la alta capacidad predictiva y discriminativa del instrumento:

a) El área de conocimiento a la que pertenece la titulación del profesor (Ciencias Experimentales, Tecnología, Humanidades y Ciencias Sociales y Jurídicas), el nivel educativo en el que enseña (Primaria, Secundaria Obligatoria o ambas) y los años de experiencia docente son las variables sociodemográficas que tienen una importante capacidad discriminativa, esto es, los niveles de tales variables marcan opiniones y valoraciones distintas en los ítems del cuestionario. Le siguen las variables sexo, provincia, grado de su titulación (diplomado o licenciado) y materias que imparte el docente, en el caso de Educación Secundaria Obligatoria. Respecto de la capacidad predictiva y de dependencia de estas mismas variables, los análisis realizados establecen con claridad que la experiencia, el área de conocimiento de la titulación del profesor, el sexo y la titularidad del centro (público, privado-concertado y privado) son las que evidencian más peso en esta relación de dependencia.

En función de lo anterior se podrían eliminar del cuestionario las variables sociodemográficas de edad (ítem 25), enseñanzas que imparte el centro (ítem 30) y puesto al que están adscritos los profesores de Primaria (ítem 33). De esta forma, la información sociodemográfica se reduciría a seis ítems que son los que verdaderamente señalan diferencias en las opiniones y valoraciones del profesorado.

b) $\mathrm{Al}$ analizar la consistencia estructural de las variables categóricas, que recogen información basada en la opinión, encontramos que entre el ítem 3 (instituciones que pueden ayudar a desarrollar mejor el sentido humano de la ciudadanía), el ítem 7 (cómo debe ser enseñada la EpC), el ítem 8 (conocimiento de las líneas oficiales para la materia) y el ítem 13 (relación entre la EpC y la innovación en los centros) existe una consistencia estructural aceptable.

Estas mismas variables, junto con la 4 (implicación de los alumnos en programas de servicio comunitario), la 5 (información del profesorado sobre la EpC), la 6 (decisión de incluir la $\mathrm{EpC}$ en el currículo), la 15 (polémica suscitada) y la 19 (cómo debe evaluarse la EpC), establecen opiniones y valoraciones distintas según el nivel de enseñanza, la experiencia y el área de conocimiento de la titulación del profesor.

Por lo tanto, podríamos prescindir, en la propuesta final del instrumento, de las variables 1 (palabras que mejor expresan el sentido humano de la ciudadanía), 9 (nivel de enseñanza con mejor predisposición hacia la materia), 10 (aspectos de los que dependerá la consolidación de la materia en el currículo), 11 (cómo afecta la 
EpC al proyecto educativo del centro), 12 (riesgo principal de la materia), 16 (razón básica de la polémica suscitada) y 20 (aspectos que afectan a la calidad en la impartición de la materia). Es decir, los análisis realizados nos permiten reducir a once (11) los ítems del instrumento que se refieren a información opinativa, cuyo montante inicial era de dieciocho (18).

c) En las variables continuas (información evaluativa), pudimos comprobar que la valoración de los temas que debería incluir la EpC (item 17), las valoraciones sobre su efectividad y los aspectos que debería enfatizar (ítem 18), lo que debe aprender un buen ciudadano (ítem 2) y las actividades que más realiza el profesorado en sus clases (ítem 21) son los que más y mejor discriminan según la experiencia, área de la titulación y nivel de enseñanza. Como puede verse, tienen una alta capacidad discriminante, además de tener estos mismos ítems una alta consistencia estructural.

Por último, refiriéndonos a su calidad técnica, son los ítems 2, 17 y 18 los que presentan unos indicadores satisfactorios de consistencia.

Debemos advertir también que el ítem 14 no se refiere a la materia, sino a la valoración que el profesorado hace de distintos aspectos sobre la enseñanza de la EpC en la escuela. Por su parte, el ítem 24, que tiene que ver con la formación del profesorado, aparece muy constreñido y relacionado con el 18, en el que se recogen los objetivos que debe establecer la materia para ser efectiva. En todo caso, estos dos ítems podrían también quedar excluidos del cuestionario, con lo que la información valorativa se reduciría, finalmente, a cuatro ítems.

Cuando diseñamos un instrumento nuevo, lo que hacemos es apoyamos en otras investigaciones, si las hay, iniciando la formulación de ítems que creemos con mayor ajuste a los objetivos que perseguimos. Sin embargo, no es infrecuente que algunos de esos ítems sean, estadísticamente, prescindibles, ya que o bien no se ajustan a lo que pretendemos medir y conocer, o bien se solapan con otros. A menudo, en las revistas de educación, nos encontramos con estudios que presentan el análisis de un instrumento de tal forma que hacen posible que otros estudios tomen esos mismos ítems como ya validados.

Justamente, el estudio del instrumento que hemos utilizado para la ocasión permitiría pasar de un cuestionario inicial de 34 ítems a uno de 21, lo cual facilitaría su administración sin perder su alta capacidad predictiva y discriminativa.

Dicho con brevedad, la investigación llevada a cabo y de la que se da cuenta en este artículo permite sostener la validez y fiabilidad, incluso para otros contextos, del instrumento objeto de evaluación. Creemos, en ese sentido, que únicamente debería procederse a la adaptación de aquellas variables ligadas a una mayor especificidad social, cultural o educativa del lugar o país en el que se pretendiera su utilización. 
REFERENCIAS BIBLIOGRÁFICAS

Azofra, J. M. (2000) Cuestionarios. Cuadernos metodológicos del CIS, n. ${ }^{\circ}$ 26. Madrid, CIS.

BANKs, J. A. (ed.) (2004) Multicultural societies in diversity and citizenship education. Global perspective. San Francisco, Jossey-Bass.

Bisquerra, R. (1987) Introducción a la estadística aplicada a la investigación educativa. Barcelona, PPU.

CARr, D. (2006) The moral roots of citizenship: reconciling principle and character in citizenship. Journal of Moral Education, 35 (4), 443-456.

Colom, A. J. y Rincón, J. C. (2007) Educación, república y nueva ciudadanía. Valencia, Tirant lo Blanch.

Education Council (2007) Council conclusions on a coherent framework of indicators and benchmarks for monitoring progress towards the Lisbon objectives in education and training. Brussel, Council of the European Union.

Escámez, J. y Gil, R. (2001) La educación en la responsabilidad. Barcelona, Paidós.

EuRYDICE (2005) Citizenship education at school in Europe. Brussel, Eurydice.

Freinet, C. (1972) La educación moral y cívica. Barcelona, Laia.

García Garrido, J. L. (2008) Derechos humanos: base de la convivencia y de la educación cívica, en Vergara, J. (coord.) Formación para la ciudadanía. Un reto de la sociedad educadora. Barcelona, Ariel, 127-138.

Hair, F. J.; Anderson, E. R.; Tatham, L. R. y Black, C. W. (1999) Análisis Multivariante. Madrid, Prentice Hall.

Hoskins, B.; Villalba, E.; Van Nijlen, D. y Barber, C. (2008) Measuring civic competence in Europe. Luxembourg, Office of the Official Publication of the European Communities.

KerLinger, N. F. (1987) Investigación del comportamiento. Técnicas y metodología. México, Interamericana.

Lee, W. O. et al. (eds.) (2004) Citizenship education in Asia and the pacific. Concepts and issues. Comparative Education Research Centre, The University of Hong Kong.

Lockyer, A.; Crick, B. y AnNette, J. (eds.) (2003) Education for democratic citizenship: issues of theory and practice. Aldershot, Ashgate.

Martín CoRTÉs, I. (2006) Una propuesta para la enseñanza de la ciudadanía democrática en España. Madrid, Fundación Alternativas.

Martínez, M.; Puig, J. M. ${ }^{a}$ y Trilla, J. (2003) Escuela, profesorado y educación moral. Teoría de la Educación, 15, 57-94.

Mayodormo, A. (1998) Aprendizaje cívico. Barcelona, Ariel.

Morales, P. (1988) Medición de actitudes en psicología y educación. Construcción de escalas y problemas metodológicos. San Sebastián, Tarttalo S.A.

Morán, M. L. (2007) Espacios y ciudadanos: los lugares de la narración clásica de la ciudadanía. Revista de Investigaciones Sociológicas, 119, 11-34.

Mucchieldi, R. (1974) El cuestionario en la encuesta psicosocial. Madrid, Ibérico Europea de Ediciones.

Muñiz, J. (2001) Teoría clásica de los tests. Madrid, Pirámide.

Ortega Ruiz, P. y Mínguez Vallejos, R. (2001) La educación moral del ciudadano de hoy. Barcelona, Paidós.

Puig, J. M. et al. (2007) Aprendizaje servicio. Educar para la ciudadanía. Barcelona, Octaedro.

Rivera, J. A. (2007) ¿Cómo educar en valores? Sobre Educación para la Ciudadanía. Claves de Razón Práctica, 176, 34-41. 
Santos Rego, M. A. y Lorenzo Moledo, M. (2007) Universidade e construcción da sociedade civil. Vigo, Edicións Xerais.

- (2009) A educación para a cidadanía e os profesores. Visión e desafío. Vigo, Edicións Xerais.

Savater, F. (2005) Educación cívica: ¿̨transversal o atravesada? El País, 1 de marzo.

- (2007) La vida eterna. Barcelona, Ariel.

Selltiz, C.; Wrightsman, S. L. y Cook, W. S. (1980) Métodos de investigación en las relaciones sociales. Madrid, Rialp.

Siegel, S. y Castellan, J. (1995) Estadística no paramétrica aplicada a las ciencias de la conducta. México, Trillas.

Torney-Purta, J.; Lehman, R.; Oswald, H. y Schulz, W. (2001) Citizenship and education in twenty-eight countries: civic knowledge and engagement at age 14. Amsterdam, IEA.

Torney-Purta, J.; SCHWILle, J. y Amadeo, J. (1999) Civic education across countries: twenty-four national case studies from the IEA Civic Education Project. Amsterdam, IEA. 
ApÉNDICE

Cuestionario N. ${ }^{\circ}$

\section{EDUCACIÓN PARA LA CIUDADANÍA Y LOS DERECHOS HUMANOS}

Buenos días/tardes. Mi nombre es y soy un investigador de la Universidad de Santiago de Compostela. Estamos desarrollando un estudio sobre aspectos relacionados con la Educación para la Ciudadanía y los Derechos Humanos (en adelante EpC). ¿Sería tan amable de concedernos unos minutos de su tiempo para contestar unas pocas preguntas? Muchas gracias. Sus respuestas serán tratadas de modo absolutamente confidencial y de una manera global (nunca analizando cuestionario a cuestionario).

Vamos a empezar hablando, en primer lugar, del contexto que rodea a la Educación para la Ciudadanía en la actualidad

1. En su opinión, ¿̇cuáles de las siguientes diría usted que son las tres palabras que mejor expresan el sentido humano de la ciudadanía? (ENTREVISTADOR: Mostrar la Tarjeta 1 y señalar un máximo de 3 palabras).

\begin{tabular}{|c|c|c|c|}
\hline 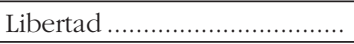 & 1 & 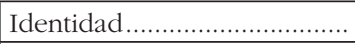 & 7 \\
\hline Participación ............................ & 2 & Igualdad ................................. & 8 \\
\hline Compromiso ........................... & 3 & 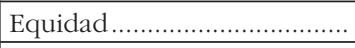 & 9 \\
\hline Responsabilidad.................... & 4 & Derechos humanos............... & 10 \\
\hline Autonomía ............................ & 5 & Democracia ........................... & 11 \\
\hline 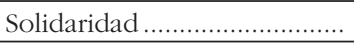 & 6 & & \\
\hline
\end{tabular}


2. En una escala desde 0 (totalmente en desacuerdo) a 10 (totalmente de acuerdo), en qué medida cree usted que para llegar a ser buenos ciudadanos nuestras niñas y nuestros niños deben aprender a ...

\begin{tabular}{|c|c|c|c|c|c|c|c|c|c|c|c|}
\hline \multirow[b]{2}{*}{ Obedecer la ley } & \multicolumn{3}{|c|}{ 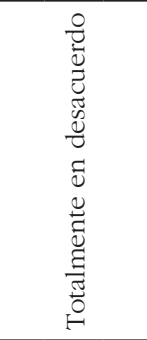 } & \multicolumn{2}{|c|}{ 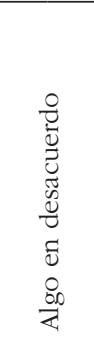 } & \multicolumn{2}{|c|}{ 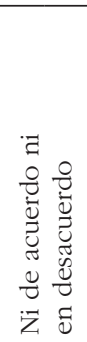 } & \multicolumn{2}{|c|}{$\begin{array}{l}0 \\
0 \\
0 \\
0 \\
0 \\
0 \\
0 \\
0 \\
0 \\
Z\end{array}$} & \multicolumn{2}{|c|}{ 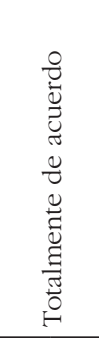 } \\
\hline & 0 & 1 & 2 & 3 & 4 & 5 & 6 & 7 & 8 & 9 & 10 \\
\hline 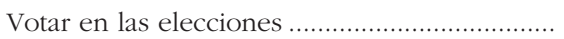 & 0 & 1 & 2 & 3 & 4 & 5 & 6 & 7 & 8 & 9 & 10 \\
\hline Afiliarse a un partido político ............................ & 0 & 1 & 2 & 3 & 4 & 5 & 6 & 7 & 8 & 9 & 10 \\
\hline Trabajar duro ....................... & 0 & 1 & 2 & 3 & 4 & 5 & 6 & 7 & 8 & 9 & 10 \\
\hline Protestar contra leyes injustas............................... & 0 & 1 & 2 & 3 & 4 & 5 & 6 & 7 & 8 & 9 & 10 \\
\hline Conocer la historia del propio país ................... & 0 & 1 & 2 & 3 & 4 & 5 & 6 & 7 & 8 & 9 & 10 \\
\hline 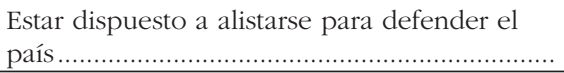 & 0 & 1 & 2 & 3 & 4 & 5 & 6 & 7 & 8 & 9 & 10 \\
\hline Preocuparse por los temas de interés político & 0 & 1 & 2 & 3 & 4 & 5 & 6 & 7 & 8 & 9 & 10 \\
\hline $\begin{array}{l}\text { Participar en actividades que ayuden a gente } \\
\text { en la comunidad....................................... }\end{array}$ & 0 & 1 & 2 & 3 & 4 & 5 & 6 & 7 & 8 & 9 & 10 \\
\hline $\begin{array}{l}\text { Mostrar respeto por los representantes del } \\
\text { gobierno } \ldots \ldots \ldots \ldots \ldots \ldots \ldots \ldots \ldots \ldots \ldots \ldots \ldots \ldots \ldots \ldots \ldots \ldots \ldots \ldots \ldots \ldots \ldots \ldots \ldots \ldots \ldots \ldots \ldots\end{array}$ & 0 & 1 & 2 & 3 & 4 & 5 & 6 & 7 & 8 & 9 & 10 \\
\hline $\begin{array}{l}\text { Tomar parte en actividades que promuevan } \\
\text { los derechos humanos ................................ }\end{array}$ & 0 & 1 & 2 & 3 & 4 & 5 & 6 & 7 & 8 & 9 & 10 \\
\hline Implicarse en el debate político ....................... & 0 & 1 & 2 & 3 & 4 & 5 & 6 & 7 & 8 & 9 & 10 \\
\hline $\begin{array}{l}\text { Tomar parte en actividades de protección del } \\
\text { medio ambiente }\end{array}$ & 0 & 1 & 2 & 3 & 4 & 5 & 6 & 7 & 8 & 9 & 10 \\
\hline 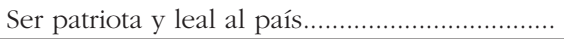 & 0 & 1 & 2 & 3 & 4 & 5 & 6 & 7 & 8 & 9 & 10 \\
\hline
\end{tabular}

3. ¿Cuál cree usted que son las instituciones que pueden ayudar a desarrollar mejor el sentido humano de la ciudadanía? (ENTREVISTADOR: No leer)

\begin{tabular}{|c|c|c|c|}
\hline Escuela & 1 & Asociaciones ....................................... & 4 \\
\hline … & 2 & 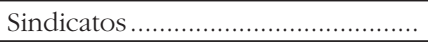 & 5 \\
\hline Ayuntamiento & 3 & Otras (ESPECIFICAR) & 6 \\
\hline
\end{tabular}

4. En general, ¿cree usted que se debe implicar a los alumnos/as desde la escuela en programas de servicio comunitario?

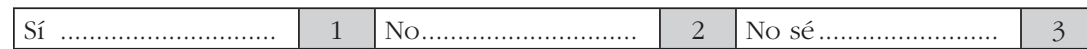


5. ¿Escuchó hablar con anterioridad de la materia Educación para la Ciudadanía y los Derechos Humanos (EpC) que se va a implantar en los centros educativos?

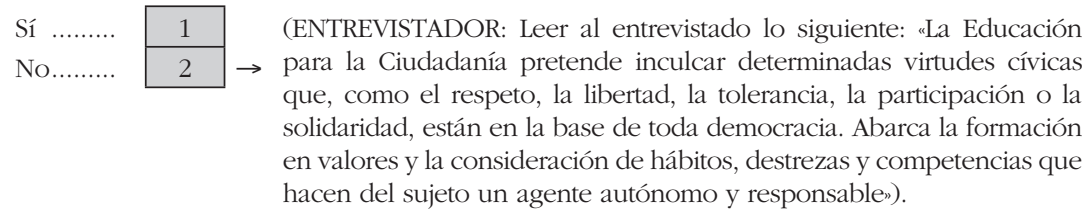

6. Como docente con experiencia, la introducción de esta materia en el currículum le parece una decisión: (ENTREVISTADOR: Leer las alternativas)

\begin{tabular}{|c|c|c|c|}
\hline Muy acertada & 1 & Con más peligros que beneficios ......................... & 3 \\
\hline Arriesgada pero necesaria... & 2 & Absolutamente equivocada...... & 4 \\
\hline
\end{tabular}

7. ¿Cómo cree usted que debería ser enseñada la EpC? (ENTREVISTADOR: Leer las opciones y que escoja solo una)

\begin{tabular}{|l|l|}
\hline Como una materia específica............................................... & 1 \\
\hline Incluida en las áreas de Humanidades y Ciencias Sociales & 2 \\
\hline Como una materia transversal ............................................ & 3 \\
\hline Como una actividad extracurricular .................................. & 4 \\
\hline
\end{tabular}

8. ¿Conoce usted las líneas concretas del MEC respecto de la materia de Educación para la Ciudadanía $(\mathrm{EpC})$ para su nivel específico de enseñanza?

\begin{tabular}{|l|l|l|l|}
\hline Sí & 1 & No & 2 \\
\hline
\end{tabular}

9. ¿En qué nivel de enseñanza cree que hay una mejor predisposición hacia esta materia?

10. ¿De qué cree usted que va depender la consolidación de esta materia en el currículum?

11. ¿Cómo cree usted que afecta esta materia al proyecto educativo del centro? 
12. ¿Cuál cree usted que es el riesgo principal de esta materia en estos momentos? (ENTREVISTADOR: Leer las alternativas)

\begin{tabular}{|l|c|}
\hline $\begin{array}{l}\text { Ser percibida como una injerencia } \\
\text { del Estado en el ámbito privado .... }\end{array}$ & 1 \\
\hline $\begin{array}{l}\text { Ser percibida como una materia para } \\
\text { adoctrinar a los alumnos................. }\end{array}$ & 2 \\
\hline $\begin{array}{l}\text { Ser percibida como una materia de } \\
\text { segunda clase ................................. }\end{array}$ & 3 \\
\hline Otra (ESPECIFICAR) ........................ & 4 \\
\hline
\end{tabular}

13. ¿Cree usted que la EpC puede ser un pilar para la innovación educativa en los centros?

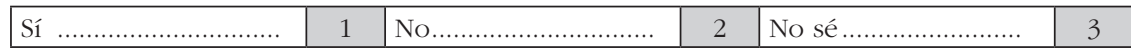

14. Respecto a la enseñanza de la EpC en la escuela, señale su grado de acuerdo en una escala desde 0 (totalmente en desacuerdo) hasta 10 (totalmente de acuerdo):

\begin{tabular}{|c|c|c|c|c|c|c|c|c|c|c|c|}
\hline & & 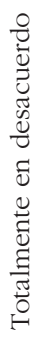 & & & & & & & & & 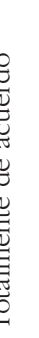 \\
\hline $\begin{array}{l}\text { Existe un amplio consenso social sobre la utilidad del } \\
\text { aprendizaje de la educación para la ciudadanía ............ }\end{array}$ & 0 & 1 & 2 & 3 & 4 & 5 & 6 & 7 & 8 & 9 & 10 \\
\hline 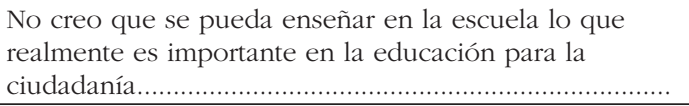 & 0 & 1 & 2 & 3 & 4 & 5 & 6 & 7 & 8 & 9 & 10 \\
\hline 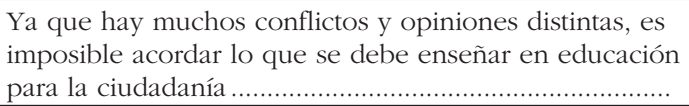 & 0 & 1 & 2 & 3 & 4 & 5 & 6 & 7 & 8 & 9 & 10 \\
\hline 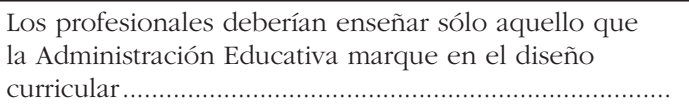 & 0 & 1 & 2 & 3 & 4 & 5 & 6 & 7 & 8 & 9 & 10 \\
\hline
\end{tabular}

15. ¿Es consciente de que la introducción de esta materia en la LOE ha desatado una cierta polémica entre algunos sectores?

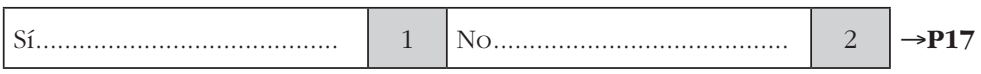


16. En su opinión, ¿̨cuál cree usted que es la razón básica de esta polémica?

Hablemos ahora de los contenidos y otros aspectos metodológicos

17. En una escala desde 0 (nada importante) a 10 (muy importante), ¿qué importancia considera usted que tienen los siguientes temas en la EpC?

\begin{tabular}{|c|c|c|c|c|c|c|c|c|c|c|c|c|}
\hline & \multicolumn{3}{|c|}{ 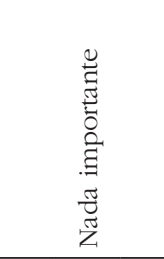 } & \multicolumn{3}{|c|}{ 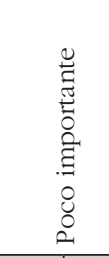 } & \multicolumn{2}{|c|}{ 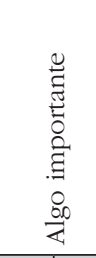 } & \multicolumn{2}{|c|}{ 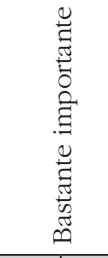 } & \multicolumn{2}{|c|}{ 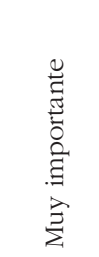 } \\
\hline Constitución y Estatuto de Autonomía & 0 & 1 & 2 & & & 4 & 5 & 6 & 7 & 8 & 9 & 10 \\
\hline $\begin{array}{l}\text { Derechos y deberes de los } \\
\text { ciudadanos } \ldots \ldots \ldots \ldots \ldots \ldots \ldots \ldots \ldots \ldots \ldots \ldots \ldots \ldots \ldots \ldots \ldots \ldots\end{array}$ & 0 & 1 & 2 & & & 4 & 5 & 6 & 7 & 8 & 9 & 10 \\
\hline $\begin{array}{l}\text { Distintas concepciones de la } \\
\text { democracia } \ldots \ldots \ldots \ldots \ldots \ldots \ldots \ldots \ldots \ldots \ldots \ldots \ldots\end{array}$ & 0 & 1 & 2 & & & 4 & 5 & 6 & 7 & 8 & 9 & 10 \\
\hline Sistema electoral del país....................... & 0 & 1 & 2 & & & 4 & 5 & 6 & 7 & 8 & 9 & 10 \\
\hline Derechos humanos............................ & 0 & 1 & 2 & & & 4 & 5 & 6 & 7 & 8 & 9 & 10 \\
\hline Organizaciones internacionales ........... & 0 & 1 & 2 & & & 4 & 5 & 6 & 7 & 8 & 9 & 10 \\
\hline 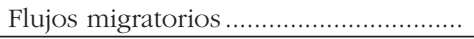 & 0 & 1 & 2 & & & 4 & 5 & 6 & 7 & 8 & 9 & 10 \\
\hline $\begin{array}{l}\text { Hechos importantes en la historia de } \\
\text { un país }\end{array}$ & 0 & 1 & 2 & & & 4 & 5 & 6 & 7 & 8 & 9 & 10 \\
\hline $\begin{array}{l}\text { Conflictos nacionales e } \\
\text { internacionales } \ldots \ldots \ldots \ldots \ldots \ldots \ldots \ldots \ldots \ldots \ldots\end{array}$ & 0 & 1 & 2 & & & 4 & 5 & 6 & 7 & 8 & 9 & 10 \\
\hline Bienestar social..................................... & 0 & 1 & 2 & & & 4 & 5 & 6 & 7 & 8 & 9 & 10 \\
\hline 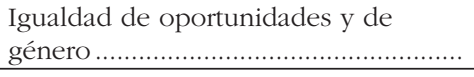 & 0 & 1 & 2 & & & 4 & 5 & 6 & 7 & 8 & 9 & 10 \\
\hline Minorías culturales ............................ & 0 & 1 & 2 & & & 4 & 5 & 6 & 7 & 8 & 9 & 10 \\
\hline Cuidado del medio ambiente .............. & 0 & 1 & 2 & & & 4 & 5 & 6 & 7 & 8 & 9 & 10 \\
\hline Propaganda y manipulación ................ & 0 & 1 & 2 & & & 4 & 5 & 6 & 7 & 8 & 9 & 10 \\
\hline Competencias cívicas ......................... & 0 & 1 & 2 & & & 4 & 5 & 6 & 7 & 8 & 9 & 10 \\
\hline Tipos de familia ..................................... & 0 & 1 & 2 & & & 4 & 5 & 6 & 7 & 8 & 9 & 10 \\
\hline Problemas de la globalización & 0 & 1 & 2 & & & 4 & 5 & 6 & 7 & 8 & 9 & 10 \\
\hline
\end{tabular}


18. En una escala desde 0 (totalmente en desacuerdo) a 10 (totalmente de acuerdo), exprese su grado de acuerdo con las siguientes frases:

\begin{tabular}{|c|c|c|c|c|c|c|c|c|c|c|c|}
\hline & \multicolumn{3}{|c|}{ 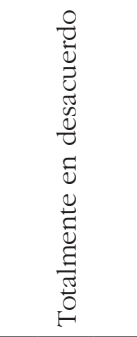 } & \multicolumn{2}{|c|}{ 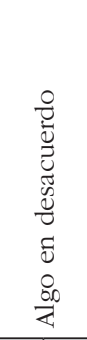 } & \multicolumn{2}{|c|}{ 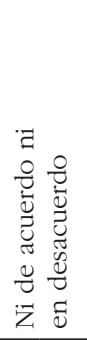 } & \multicolumn{2}{|c|}{$\begin{array}{l}0 \\
0 \\
0 \\
0 \\
0 \\
0 \\
0 \\
0 \\
0 \\
00 \\
Z\end{array}$} & \multicolumn{2}{|c|}{ 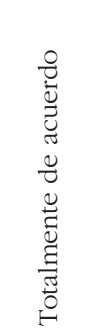 } \\
\hline $\begin{array}{l}\text { La efectividad de la EpC depende de que los } \\
\text { estudiantes aprendan a cooperar con sus iguales }\end{array}$ & 0 & 1 & 2 & 3 & 4 & 5 & 6 & 7 & 8 & 9 & 10 \\
\hline $\begin{array}{l}\text { La efectividad de la EpC depende de que los } \\
\text { estudiantes aprendan cuáles son y cómo funcionan } \\
\text { las estructuras del gobierno en una democracia }\end{array}$ & 0 & 1 & 2 & 3 & 4 & 5 & 6 & 7 & 8 & 9 & 10 \\
\hline $\begin{array}{l}\text { La efectividad de la EpC depende de que los } \\
\text { estudiantes aprendan cómo ayudar a resolver } \\
\text { problemas en la comunidad ............................ }\end{array}$ & 0 & 1 & 2 & 3 & 4 & 5 & 6 & 7 & 8 & 9 & 10 \\
\hline $\begin{array}{l}\text { La EpC debería enfatizar el desarrollo del } \\
\text { pensamiento crítico en los estudiantes .............. }\end{array}$ & 0 & 1 & 2 & 3 & 4 & 5 & 6 & 7 & 8 & 9 & 10 \\
\hline $\begin{array}{l}\text { La EpC debería enfatizar el conocimiento sobre la } \\
\text { sociedad }\end{array}$ & 0 & 1 & 2 & 3 & 4 & 5 & 6 & 7 & 8 & 9 & 10 \\
\hline 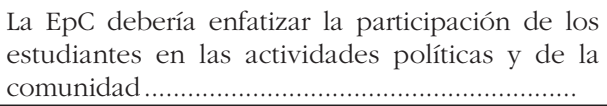 & 0 & 1 & 2 & 3 & 4 & 5 & 6 & 7 & 8 & 9 & 10 \\
\hline $\begin{array}{l}\text { La EpC debería enfatizar el desarrollo de valores } \\
\text { democráticos en los estudiantes......................... }\end{array}$ & 0 & 1 & 2 & 3 & 4 & 5 & 6 & 7 & 8 & 9 & 10 \\
\hline
\end{tabular}

19. ¿Cómo cree usted que debería ser evaluada la EpC? (ENTREVISTADOR: Respuesta múltiple. El entrevistado puede escoger más de una opción)

\begin{tabular}{|l|l|l|l|}
\hline Ensayos o composiciones escritas ... & 1 & Experiencias de participación cívica & 4 \\
\hline Tests de elección múltiple .............. & 2 & Otras (ESPECIFICAR) .................... & 5 \\
\hline Exámenes o pruebas orales ............ & 3 & Ninguna evaluación ........................ & 6 \\
\hline
\end{tabular}


¿QUÉ ES LO QUE IMPORTA EN EDUCACIÓN PARA LA CIUDADANÍA?

20. En su opinión, ¿qué tres aspectos de los siguientes necesitaría su escuela para impartir esta materia con calidad?

\begin{tabular}{|l|c|l|c|}
\hline Materiales y libros de texto ........... & 1 & $\begin{array}{l}\text { Más cooperación escuela- } \\
\text { organizaciones cívicas .................. }\end{array}$ & 5 \\
\hline Formación específica en la materia & 2 & $\begin{array}{l}\text { Más oportunidades para proyectos } \\
\text { innovadores ................................ }\end{array}$ & 6 \\
\hline $\begin{array}{l}\text { Más cooperación entre profesores } \\
\text { de distintas áreas .......................... }\end{array}$ & 3 & $\begin{array}{l}\text { Más recursos para actividades } \\
\text { extraescolares .............................. }\end{array}$ & 7 \\
\hline Más tiempo dedicado a la materia . & 4 & $\begin{array}{l}\text { Más autonomía para decidir sobre } \\
\text { la materia ...................................... }\end{array}$ & 8 \\
\hline
\end{tabular}

21. En una escala desde 0 (nunca) a 10 (siempre), ¿con que frecuencia diría usted que realiza las siguientes actividades en sus clases?

\begin{tabular}{|c|c|c|c|c|c|c|c|c|c|c|c|}
\hline & \multicolumn{3}{|c|}{$\stackrel{\widetilde{U}}{\Xi}$} & \multicolumn{2}{|c|}{ 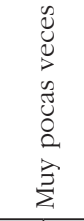 } & \multicolumn{2}{|c|}{ 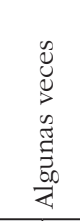 } & \multicolumn{2}{|c|}{ 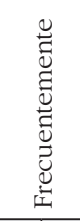 } & \multicolumn{2}{|c|}{ 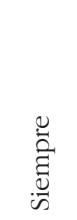 } \\
\hline $\begin{array}{l}\text { Los estudiantes trabajan en proyectos que implican } \\
\text { reunir información fuera de la clase } \ldots \ldots \ldots \ldots \ldots \ldots \ldots \ldots \ldots \ldots\end{array}$ & 0 & 1 & 2 & 3 & 4 & 5 & 6 & 7 & 8 & 9 & 10 \\
\hline Los alumnos estudian a través de libros de texto ............. & 0 & 1 & 2 & 3 & 4 & 5 & 6 & 7 & 8 & 9 & 10 \\
\hline $\begin{array}{l}\text { Los alumnos trabajan con bancos de actividades/ } \\
\text { problemas } \ldots \ldots \ldots \ldots \ldots \ldots \ldots \ldots \ldots \ldots \ldots \ldots \ldots \ldots \ldots \ldots \ldots \ldots \ldots \ldots \ldots \ldots \ldots \ldots \ldots \ldots \ldots \ldots \ldots \ldots \ldots \ldots \ldots \ldots \ldots \ldots \ldots\end{array}$ & 0 & 1 & 2 & 3 & 4 & 5 & 6 & 7 & 8 & 9 & 10 \\
\hline 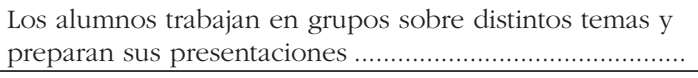 & 0 & 1 & 2 & 3 & 4 & 5 & 6 & 7 & 8 & 9 & 10 \\
\hline Usted imparte la clase y los alumnos toman apuntes....... & 0 & 1 & 2 & 3 & 4 & 5 & 6 & 7 & 8 & 9 & 10 \\
\hline Usted hace preguntas y los alumnos responden............... & 0 & 1 & 2 & 3 & 4 & 5 & 6 & 7 & 8 & 9 & 10 \\
\hline $\begin{array}{l}\text { Los estudiantes participan en simulaciones y role-playing } \\
\text { adoptando distintos papeles } \ldots \ldots \ldots \ldots \ldots \ldots \ldots \ldots \ldots \ldots \ldots \ldots \ldots . .\end{array}$ & 0 & 1 & 2 & 3 & 4 & 5 & 6 & 7 & 8 & 9 & 10 \\
\hline Usted hace debates sobre temas polémicos en la clase & 0 & 1 & 2 & 3 & 4 & 5 & 6 & 7 & 8 & 9 & 10 \\
\hline 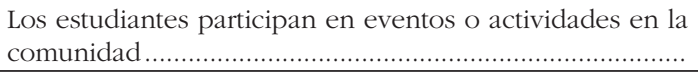 & 0 & 1 & 2 & 3 & 4 & 5 & 6 & 7 & 8 & 9 & 10 \\
\hline
\end{tabular}

\section{$\underline{\text { Por último, tratemos de algunas cuestiones referidas al profesorado }}$}

22. En su opinión, ¿qué Profesor/a cree usted que debe impartir la EpC en Primaria?
23. ¿Y en Secundaria Obligatoria?

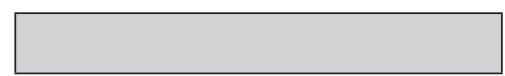


24. En una escala desde 0 (totalmente en desacuerdo) a 10 (totalmente de acuerdo), exprese o su grado de acuerdo con las siguientes frases:

\begin{tabular}{|c|c|c|c|c|c|c|c|c|c|c|c|}
\hline & & 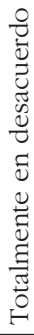 & & & & & & & & & 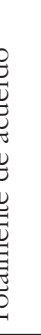 \\
\hline $\begin{array}{l}\text { El profesorado cuenta con formación suficiente para } \\
\text { asumir con garantías esta materia } \ldots \ldots \ldots \ldots \ldots \ldots \ldots \ldots \ldots \ldots\end{array}$ & 0 & 1 & 2 & 3 & 4 & 5 & 6 & 7 & 8 & 9 & 10 \\
\hline $\begin{array}{l}\text { Es necesario un plan específico de formación del } \\
\text { profesorado en esta área......................................... }\end{array}$ & 0 & 1 & 2 & 3 & 4 & 5 & 6 & 7 & 8 & 9 & 10 \\
\hline 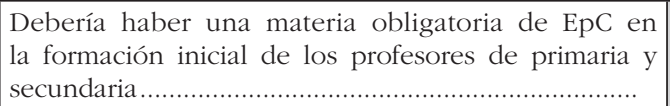 & 0 & 1 & 2 & 3 & 4 & 5 & 6 & 7 & 8 & 9 & 10 \\
\hline Son necesarias asesorías de formación específica en & 0 & 1 & 2 & 3 & 4 & 5 & 6 & 7 & 8 & 9 & 10 \\
\hline $\begin{array}{l}\text { La EpC puede contribuir a mejorar la imagen social de } \\
\text { los profesores }\end{array}$ & 0 & 1 & 2 & 3 & 4 & 5 & 6 & 7 & 8 & 9 & 10 \\
\hline
\end{tabular}

\section{Vamos a finalizar esta entrevista con una serie de cuestiones sociodemográficas}

25. ¿Podría decirme su edad? años cumplidos.

26. Sexo.

\begin{tabular}{|l|l|l|l|}
\hline Hombre .......................................... & 1 & Mujer ........................................ & 2 \\
\hline
\end{tabular}

27. Titulación, o titulaciones, que posee:

28. Años de experiencia en la enseñanza:

29. Titularidad del centro

\begin{tabular}{|c|c|c|c|}
\hline Público ............................................ & 1 & 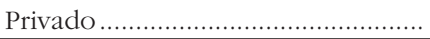 & 3 \\
\hline Privado Concertado........................ & 2 & Otras (ESPECIFICAR)..................... & 4 \\
\hline
\end{tabular}


30. Enseñanzas que se imparten en su centro

\begin{tabular}{|c|c|c|c|}
\hline Educación Infantil............................. & 1 & Ciclos Formativos ............................ & 5 \\
\hline Educación Primaria............................. & 2 & Enseñanzas Especiales ...................... & 6 \\
\hline Educación Secundaria Obligatoria.... & 3 & Educación de Adultos ....................... & 7 \\
\hline 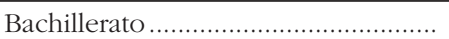 & 4 & Otras (ESPECIFICAR) ........................ & 8 \\
\hline
\end{tabular}

31. Curso y Nivel en los que enseña el entrevistado/a (puede marcar más de una opción)

\begin{tabular}{|c|c|c|c|}
\hline 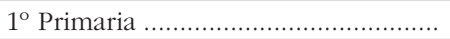 & 1 & 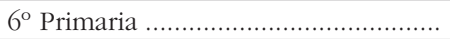 & 6 \\
\hline 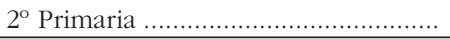 & 2 & 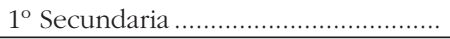 & 7 \\
\hline 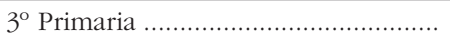 & 3 & 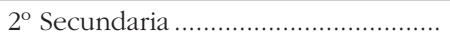 & 8 \\
\hline 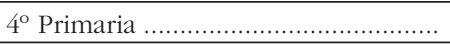 & 4 & 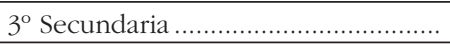 & 9 \\
\hline $5^{\circ}$ Primaria & 5 & $4^{\circ}$ Secundaria ................... & 10 \\
\hline
\end{tabular}

32. Entre las materias que imparte dentro de su especialidad, ¿en cuál de ellas tiene usted una mayor carga docente? (ENTREVISTADOR: Sólo para los que dan clase en ESO)

33. Como maestro/a, ¿a qué puesto está usted adscrito? (ENTREVISTADOR: Sólo para los que dan clase en PRIMARIA)

\begin{tabular}{|c|c|c|c|}
\hline FF (Filología francesa) & 1 & 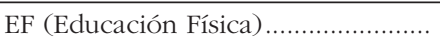 & 5 \\
\hline 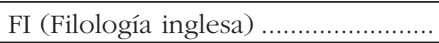 & 2 & AL (Audición y Lenguaje) ................ & 6 \\
\hline PT (Pedagogía Terapéutica) ............ & 3 & EP (Educación Primaria) ........................ & 7 \\
\hline EM (Educación Musical). & 4 & & \\
\hline
\end{tabular}

\section{MUCHAS GRACIAS POR SU COLABORACIÓN}

(Entrevistador: Anotar además los siguientes datos)

34. Localización del centro

\begin{tabular}{|l|l|l|}
\hline Calle & Ciudad (municipio) & Provincia \\
\hline
\end{tabular}

